\title{
Improved analysis of all-sky meteor radar measurements of gravity wave variances and momentum fluxes
}

\author{
V. F. Andrioli ${ }^{1}$, D. C. Fritts ${ }^{2}$, P. P. Batista ${ }^{1}$, and B. R. Clemesha ${ }^{1}$ \\ ${ }^{1}$ National Institute for Space Research, São José dos Campos, SP, Brazil \\ ${ }^{2}$ GATS/Boulder, Boulder, CO, USA
}

Correspondence to: V. F. Andrioli (vania@laser.inpe.br)

Received: 1 November 2012 - Revised: 5 March 2013 - Accepted: 15 April 2013 - Published: 23 May 2013

\begin{abstract}
The advantages of using a composite day analysis for all-sky interferometric meteor radars when measuring mean winds and tides are widely known. On the other hand, problems arise if this technique is applied to Hocking's (2005) gravity wave analysis for all-sky meteor radars. In this paper we describe how a simple change in the procedure makes it possible to use a composite day in Hocking's analysis. Also, we explain how a modified composite day can be constructed to test its ability to measure gravity wave momentum fluxes. Test results for specified mean, tidal, and gravity wave fields, including tidal amplitudes and gravity wave momentum fluxes varying strongly with altitude and/or time, suggest that the modified composite day allows characterization of monthly mean profiles of the gravity wave momentum fluxes, with good accuracy at least at the altitudes where the meteor counts are large (from 89 to $92.5 \mathrm{~km}$ ). In the present work we also show that the variances measured with Hocking's method are often contaminated by the tidal fields and suggest a method of empirical correction derived from a simple simulation model. The results presented here greatly increase our confidence because they show that our technique is able to remove the tide-induced false variances from Hocking's analysis.
\end{abstract}

Keywords. Meteorology and atmospheric dynamics (Middle atmosphere dynamics)

\section{Introduction}

Atmospheric gravity waves (GWs) have been studied intensely in recent years because of the important role they play in atmospheric dynamics. Several techniques have been used to measure GW in the mesosphere and lower thermosphere region. Due to the short period and vertical wavelength involved, normally only methods that provide high temporal and vertical resolution are used to infer directly the gravity wave parameters. Meteor radars are appropriate instruments for comparative studies of low-frequency movements in the MLT region at different sites since there is a worldwide network of meteor radars equipped with almost identical hardware and software. According to Hocking (private communication) there are about 25 SKiYMET all-sky radars in operation around the world, but these radars do not provide direct measurements of gravity waves. Hocking (2005) proposed a new technique for analyzing the data from these radars, making it possible to derive indirect effects of the gravity waves in terms of the zonal and meridional components of GW variances and momentum fluxes.

A number of results obtained by applying Hocking's analysis have been published in the literature. These include Antonita et al. (2008) for Trivandrum in the tropics, Clemesha et al. (2009) at three low-latitude locations in Brazil, Fritts et al. (2010) for Tierra del Fuego at middle latitude, Placke et al. (2011b) for Collm at middle latitude, and Placke et al. (2011a) at three locations in Europe. While the main aim of Hocking's analysis is the study of GW momentum fluxes, Vincent et al. (2010) showed that it is necessary to average for more than one month to get useful results for traditional meteor radars, basically because determination of the momentum fluxes requires the measurement of small vertical velocities. In this paper we present an improvement in the analysis of the traditional meteor radar data that allow us to infer at least a monthly mean of GW momentum fluxes using Hocking's analysis. At the same time, GW variances are easier to measure than momentum fluxes, with much shorter integration times, and are also a useful indicator of GW 
activity. Hocking's (2005) analysis assumes that any shortterm fluctuation in the meteor wind, not caused by prevailing winds, must be due to GW. In order to see if the variances measured by Hocking's analysis are solely due to GW, we have made some simulations and have noted that in the presence of tides with short vertical wavelength, the variances increase and are modulated at the tidal period. Then, the improvement in Hocking's (2005) analysis consists in eliminating the tidal apparent variances from the values inferred by this technique. Our aims in this paper are (1) to propose a modified composite day as a way to overcome the issue of low meteor counting in the analysis of all-sky meteor radar measurements for GW momentum flux determination, (2) to investigate the possible contamination of the variances derived from Hocking's analysis by tides, (3) to propose a correction technique using a simple simulation model, and (4) to evaluate the ability of the Brazilian meteor radars to measure GW momentum flux using the improved analysis.

\section{Modified composite day analysis}

In the analysis of geophysical data, it is often required to generate the average diurnal variation of a parameter on the basis of many days of data. The simplest way to do this is to divide the data into fixed time intervals of $1 \mathrm{~h}$, for example, and then average across all the data available for each given time bin. In the case of meteor radar data this is not necessarily the best procedure. An all-sky meteor radar (Hocking et al., 2001) measures the position and radial velocity of meteor echoes. The average wind vectors that best fit the radial velocities determined for a given time/height bin (comprising intervals of $1 \mathrm{~h}$ and $1 \mathrm{~km}$, for example) are then found. It is easy to see that a minimum of three meteors must be detected to determine a 3-dimensional wind vector. In practice a least-mean-squares fitting procedure is normally used and a number of meteor echoes, usually not less than 7 , is desirable in order to minimize noise, both instrumental and geophysical. The SKiYMET meteor radars located in Brazil provide typically around 3000 useful echoes per day, giving a typically time resolution of $1 \mathrm{~h}$ and height resolution ranging from 2 to $3 \mathrm{~km}$, for measuring winds when 1 day of data is used. However, due to the large diurnal variation in the meteor detection, there are some gaps where this resolution is not reached. Hence, this procedure works well when the meteor counts are high, but under some conditions insufficient meteors are detected in some time/height bins to provide adequate statistics. It is possible to circumvent this problem by accumulating the echoes in any given time/height bin over many days up to a month for example, and then analyzing them as if they belonged to a single day, which is then referred to as a composite day. This is the method generally used by many workers (e.g., Andrioli et al., 2009; Batista et al., 2004) for determining monthly average winds from meteor radar data. Its advantage is, of course, that it allows one to determine reliable average wind values for time/height bins where the meteor count is too low for individual daily values to be determined accurately.

To use Hocking's (2005) analysis, first it is necessary to determine a fitted wind vector for each time/height bin, as described above, and then use this vector to compute a fitted radial velocity for each meteor detected. It is then assumed that the difference between any given measured radial velocity and the fitted radial velocity is due to the contribution of GWs. On this basis it is possible to compute the meridional, zonal, and vertical fluctuating wind velocities and the vertical flux of horizontal momentum (see Hocking, 2005, for details). As in the case of the mean wind, a minimum number of meteor echoes are required to obtain statistically meaningful results. In practice not less than 30 meteor echoes are needed, suggesting that we should use the composite day analysis if we want to obtain meaningful results when meteor counts are low. The problem with this procedure, however, is that day-to-day wind variations due to changes in the prevailing winds, tides, and planetary waves will all contribute to the fluctuating wind velocities, artificially inflating our estimates of GW variances. Here we describe a simple technique that enables us to use the composite day method in order to get enough meteor echoes to estimate the variance and momentum flux, while minimizing the "contamination" caused by tides, planetary waves, and prevailing winds.

As described above, Hocking's technique assumes that the differences between individual measured radial velocities and best fit radial velocities (hereafter referred to as $v_{\text {rad }}^{\prime}$ ), are a manifestation of GW winds. If we apply the composite day technique to data to be analyzed in this way, the best fit vector velocity is computed over the entire data set for each given time/height bin, resulting in a single vector velocity for each bin. The radial velocity corresponding to this vector will then be subtracted from each measured radial velocity for the given bin, resulting in variances which incorporate the day-to-day variations in prevailing winds, planetary waves, tides, etc. A simple change in procedure overcomes this problem. Instead of using a single fitted vector velocity for each overall time/height bin, we compute a fitted velocity for each time/height interval for each day to be included in the composite day. That means we will make a preanalysis before building the composite day. In other words, we infer the values of $v_{\text {rad }}^{\prime}$ for each time interval and day separately and associate them with the meteor echo position information through the entire data set. Determination of the velocities is possible so long as we have at least 7 echoes in each time/height interval, a condition much easier to fulfill than the 30 echoes needed for a direct analysis of individual intervals, as mentioned earlier. In this way the values of $v_{\text {rad }}^{\prime}$ do not suffer a major contribution from tidal day-to-day variation and planetary waves. The modified composite day is then built by accumulating the $v_{\text {rad }}^{\prime}$ and the geometrical parameters of each meteor echo in its respective time/height interval throughout the month as if they belonged to a single 

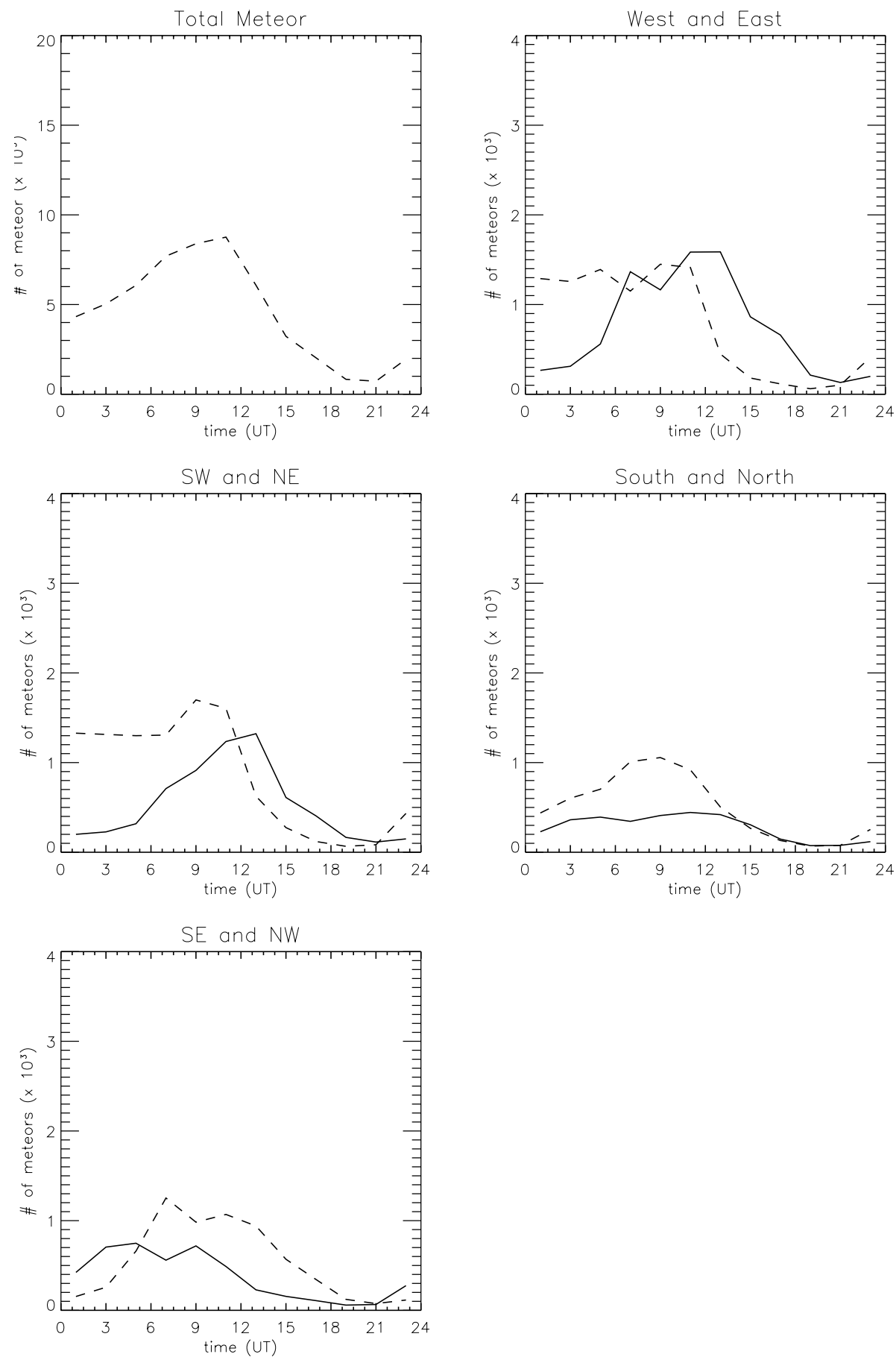

Fig. 1. Meteor distribution for Cachoeira Paulista $\left(23^{\circ} \mathrm{S}, 45^{\circ} \mathrm{W}\right)$ during October 2005. Dashed lines indicate the first component specified above each graph. For example, the dashed line in the top right panel means west and the solid line means east.

day. In the following sections of this paper we test the ability of this method to extract GW variances and fluxes without significant contamination.

\subsection{Method of simulation}

With the purpose of comparison and evaluation of our improvement in the method of analysis, we use three different types of analysis: (1) direct day-by-day analysis, excluding time/height intervals containing less than 30 meteor 
echoes, followed by simple averaging; (2) conventional composite day analysis; (3) modified composite day analysis as described above. We will refer to these methods as "direct analysis", "composite day analysis", and "modified composite day analysis", respectively, and we will use plots of the meridional wind variance to illustrate the results. In order to best evaluate the three different methods, we use a simple model to simulate background winds and GW propagation. We have used a real spatial meteor distribution from one of our meteor radars located at Cachoeira Paulista $\left(23^{\circ} \mathrm{S}\right.$, $\left.45^{\circ} \mathrm{W}\right),(\mathrm{CP})$, and also we have chosen a month in which the meteor count was very low, October 2005 (shown in Fig. 1), in order to demonstrate the ability of the modified composite day in overcoming this issue (low meteor counts). The meteor radar at CP is a SKiYMET radar, and it uses an uncrossed Yagi Tx antenna that transmits pulses at a carrier frequency of $35.24 \mathrm{MHz}$ and rep rate of $2144 \mathrm{~Hz}$, with five receiver antennae. The peak power was $6 \mathrm{~kW}$ before November 2001, after which it was changed to $12 \mathrm{~kW}$. The meteor distribution, presented in Fig. 1, was separated into 8 uniformly distributed sectors, each with $45^{\circ}$ width. In this model we replaced the measured radial velocities with velocities calculated from the following equations:

$$
\begin{aligned}
U(x, y, z, t) & =U_{\mathrm{M}}+U_{2 \mathrm{D}}(t) \sin \left(2 \pi t / T_{2 \mathrm{D}}\right) \\
& +U_{D}(z, t) \sin \left(2 \pi\left(t-\delta_{\mathrm{UD}}\right) / T_{\mathrm{D}}\right) \\
& +U_{\mathrm{SD}}(z, t) \sin \left(2 \pi\left(t-\delta_{\mathrm{USD}}\right) / T_{\mathrm{SD}}\right) \\
s & +U_{\mathrm{GW} 1}(x, y, z, t) \sin \left(k_{1} x+l_{1} y+m_{1} z\right. \\
& \left.-2 \pi t / T_{\mathrm{GW} 1}\right) \\
& +U_{\mathrm{GW} 2}(x, y, z, t) \sin \left(k_{2} x+l_{2} y+m_{2} z\right. \\
& \left.-2 \pi t / T_{\mathrm{GW} 2}\right) \\
& +U_{\mathrm{GW} 3}(x, y, z, t) \sin \left(k_{3} x+l_{3} y+m_{3} z\right. \\
& \left.-2 \pi t / T_{\mathrm{GW} 3}\right) \\
& +U_{\mathrm{GW} 4}(x, y, z, t) \sin \left(k_{4} x+l_{4} y+m_{4} z\right. \\
& \left.-2 \pi t / T_{\mathrm{GW} 4}\right),
\end{aligned}
$$

$$
\begin{aligned}
V(x, y, z, t) & =V_{\mathrm{M}}+V_{2 \mathrm{D}}(t) \sin \left(2 \pi t / T_{2 \mathrm{D}}\right) \\
& -V_{\mathrm{D}}(z, t) \cos \left(2 \pi\left(t-\delta_{\mathrm{UD}}\right) / T_{\mathrm{D}}\right) \\
& -V_{\mathrm{SD}}(z, t) \cos \left(2 \pi\left(t-\delta_{\mathrm{USD}}\right) / T_{\mathrm{SD}}\right) \\
& +V_{\mathrm{GW} 1}(x, y, z, t) \sin \left(k_{1} x+l_{1} y+m_{1} z\right. \\
& \left.-2 \pi t / T_{\mathrm{GW} 1}\right) \\
& +V_{\mathrm{GW} 2}(x, y, z, t) \sin \left(k_{2} x+l_{2} y+m_{2} z\right. \\
& \left.-2 \pi t / T_{\mathrm{GW} 2}\right) \\
& +V_{\mathrm{GW} 3}(x, y, z, t) \sin \left(k_{3} x+l_{3} y+m_{3} z\right. \\
& \left.-2 \pi t / T_{\mathrm{GW} 3}\right) \\
& +V_{\mathrm{GW} 4}(x, y, z, t) \sin \left(k_{4} x+l_{4} y+m_{4} z\right. \\
& \left.-2 \pi t / T_{\mathrm{GW} 4}\right),
\end{aligned}
$$

$$
\begin{aligned}
W(x, y, z, t) & =W_{\mathrm{GW} 1}(x, y, z, t) \sin \left(k_{1} x+l_{1} y+m_{1} z\right. \\
& \left.-2 \pi t / T_{\mathrm{GW} 1}\right) \\
& +W_{\mathrm{GW} 2}(x, y, z, t) \sin \left(k_{2} x+l_{2} y+m_{2} z\right. \\
& \left.-2 \pi t / T_{\mathrm{GW} 2}\right) \\
& +W_{\mathrm{GW} 3}(x, y, z, t) \sin \left(k_{3} x+l_{3} y+m_{3} z\right. \\
& \left.-2 \pi t / T_{\mathrm{GW} 3}\right) \\
& +W_{\mathrm{GW} 4}(x, y, z, t) \sin \left(k_{4} x+l_{4} y+m_{4} z\right. \\
& \left.-2 \pi t / T_{\mathrm{GW} 4}\right)
\end{aligned}
$$

and

$$
\begin{aligned}
V_{\mathrm{rad}}= & U(x, y, z, t) \sin \theta \cos \varphi+V(x, y, z, t) \sin \theta \sin \varphi \\
& +W(x, y, z, t) \cos \theta,
\end{aligned}
$$

where $U, V$, and $W$ are zonal, meridional, and vertical amplitudes of the wind; $V_{\text {rad }}$ is the radial velocity calculated for each meteor; zenith and azimuth position $\theta, \varphi$ are where the azimuth respectively starts on east and rotates counterclockwise; $(x, y, z)$ are the position; $(k, l, m)$ are the zonal, meridional, and vertical wave numbers; $t$ is the time when each meteor was measured; and $T$ is the wave period:

- $U_{\mathrm{M}}$ and $V_{\mathrm{M}}$ are zonal and meridional mean winds;

- $U_{2 \mathrm{D}}$ and $V_{2 \mathrm{D}}$ are the zonal and meridional 2-day planetary wave components;

- $\left(U_{\mathrm{D}}, V_{\mathrm{D}}\right)$ and $\left(U_{\mathrm{SD}}, V_{\mathrm{SD}}\right)$ are diurnal and semidiurnal tides having zonal and meridional amplitudes assumed to rotate counter clockwise with time and which may have either constant or varying amplitudes with increasing altitude;

- $W_{0}=0$ for all the cases;

- $\left(\delta_{\mathrm{UD}}, \delta_{\mathrm{VD}}\right)$ and $\left(\delta_{\mathrm{USD}}, \delta_{\mathrm{VSD}}\right)$ are diurnal and semidiurnal tidal phases varying according to the vertical wavelengths;

- $T_{2 \mathrm{D}}, T_{\mathrm{D}}$, and $T_{\mathrm{SD}}$ are the wave periods, $48 \mathrm{~h}, 24 \mathrm{~h}$, and $12 \mathrm{~h}$, respectively.

- GW amplitudes $\left(U_{\mathrm{GW}}, V_{\mathrm{GW}}, W_{\mathrm{GW}}\right)$ were simulated as traveling waves having zonal, meridional or oblique propagation, spatial and temporal variability, correlated horizontal and vertical motions, and constant or variable momentum fluxes; and stationary mountain waves having zonal and meridional propagation, only spatial variability, correlated horizontal and vertical motions, and constant momentum fluxes.

The equations and the tests used in the present model were based on Fritts et al. (2010). The main differences between their equation system and ours are that we simulate tides having phase propagation and also we simulate 2-day planetary waves, while they did not. Fritts et al. (2010) did not take into account tidal phase propagation because at Tierra del Fuego 

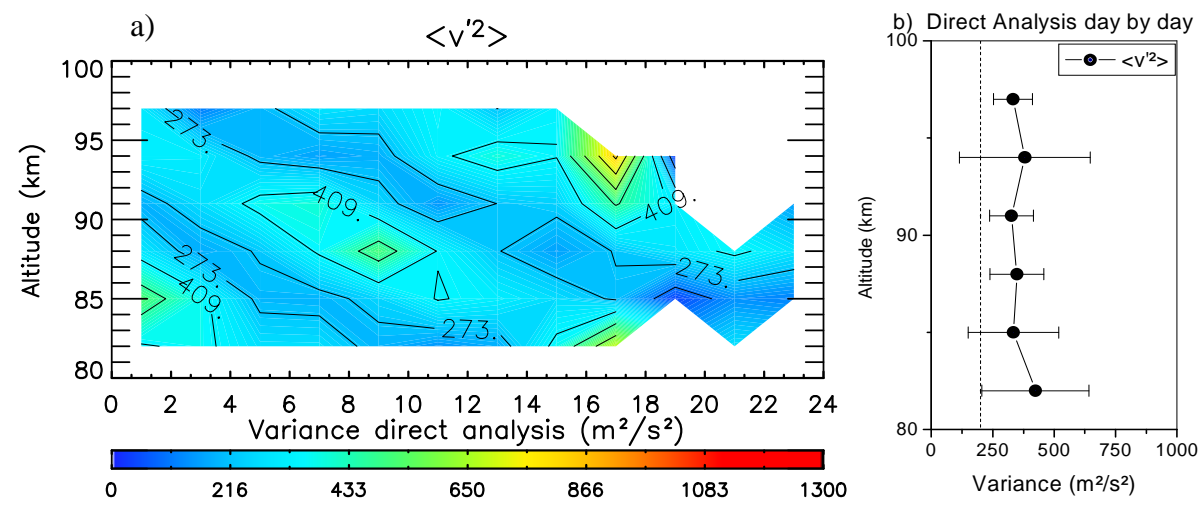

Fig. 2. (a) Contour plot of $24 \mathrm{~h}$ variation of meridional variance as a function of height for direct analysis with simple averaging of daily values. (b) Monthly mean meridional variance (black circles) and standard deviations.
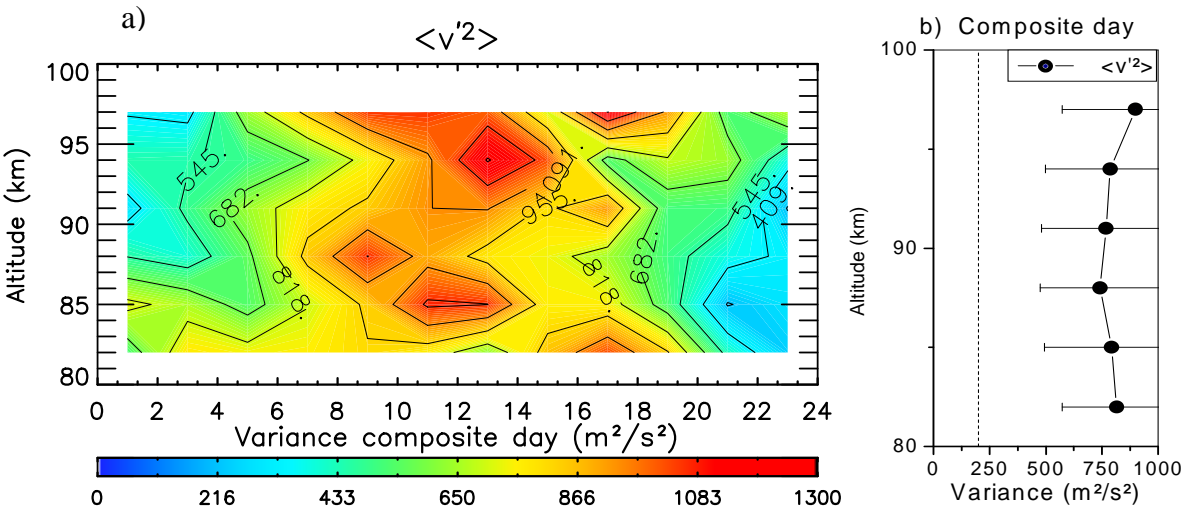

Fig. 3. As Fig. 2, but using the standard composite day analysis.

(midlatitude) the semidiurnal tide with large vertical wavelength is dominant. But at middle and low latitudes, where our radars are located, the diurnal tide with short vertical wavelength is dominant, and we are interested in investigating the possible tidal influence on the extraction of GW variances and momentum fluxes. The mean wind, tidal, and GW amplitudes and spatial and temporal parameters are listed in Table 1 for the five test cases that will be considered. Results for each case are discussed below. The expected radial velocity for each detected meteor echo was calculated on the basis of this model at the same time and position (measured range, azimuth and zenith angle) as were measured by the meteor radar.

\subsection{Examples showing the three different methods of using Hocking's analysis}

Since we are using model simulations, we know the analytical values of the momentum flux and the variances due to the GW present in our simulation, allowing us to determine which method best recovers the expected values. All the analyses were made using $2 \mathrm{~h}$ (plus $1 \mathrm{~h}$ overlap), and $3 \mathrm{~km}$ time/height bins. For the present evaluation we have used the parameters shown in Table 1 for Case 0 . In this case we consider background winds that suppose the presence of a constant mean wind, and a 2-day planetary wave that has a random day-to-day amplitude variability, in which the amplitude varies randomly from 0 to $5 \mathrm{~m} \mathrm{~s}^{-1}$ from one day to the next. Also, we have assumed diurnal and semidiurnal tides with vertical wavelengths of $25 \mathrm{~km}$ and $50 \mathrm{~km}$, respectively, and GWs having horizontal variations, with 50 and $100 \mathrm{~km}$ wavelengths in the zonal and meridional motions, respectively (see Table 1).

In Fig. 2a we show a contour plot of the average variance computed using direct analysis, and the height profile shown in Fig. 2b shows a time average of this plot. Figures 3 and 4 show the same plots for the composite day analysis and the modified composite day analysis, respectively, for the same case. Referring to Fig. 2a we can see that there are eight time/height bins for which there are no data; these correspond to intervals for which there was no day with at least 30 meteor echoes. For the composite day analysis, shown in Fig. 3a, there are no intervals without data, i.e., no bins with less than 30 accumulated meteor echoes. For the modified composite day analysis, shown in Fig. 4, there is only one bin without data, i.e., there was only one height/time bin for 
a)

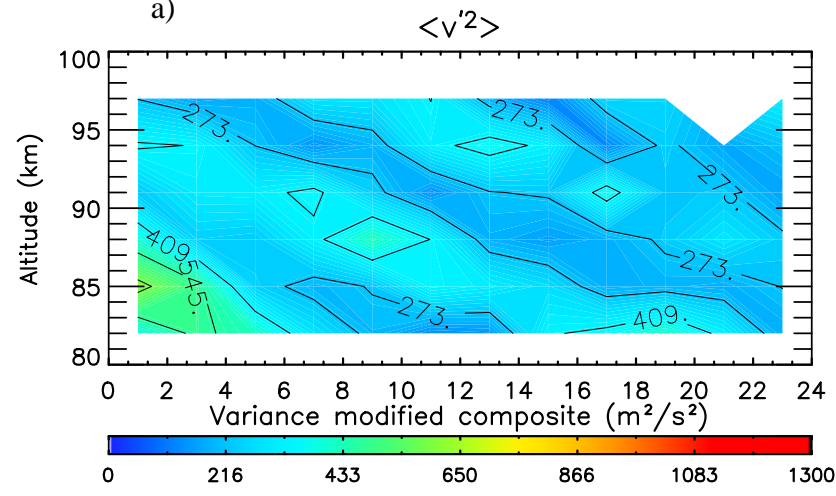

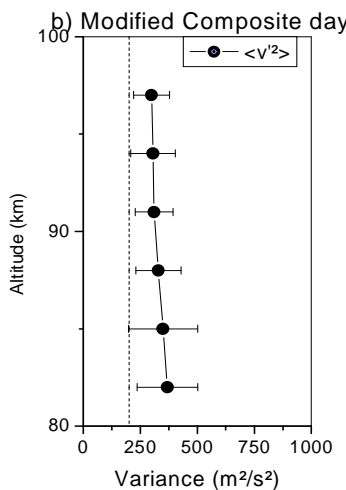

Fig. 4. As Fig. 2, but using the modified composite day analysis.

Table 1. Mean, tidal, planetary wave, and GW parameters* used for test cases evaluating modified composite day of CP SKiYMET measurement capabilities employing real meteor distributions and test motion fields. Source: adapted from Fritts et al. (2010).

\begin{tabular}{|c|c|c|c|c|c|}
\hline Parameter & Case 0 & Case 1 & Case 2 & Case 3 & Case 4 \\
\hline$U_{\mathrm{M}}, V_{\mathrm{M}}$ & 10,5 & 10,5 & 10,5 & $40,-20$ & $-20,-10$ \\
\hline$U_{\mathrm{D}}, V_{\mathrm{D}}$ & 40,40 & 40,40 & 40,40 & 20,20 & 40,40 \\
\hline$\lambda_{\mathrm{D}}$ & $25 \mathrm{~km}$ & $25 \mathrm{~km}$ & $25 \mathrm{~km}$ & $25 \mathrm{~km}$ & $25 \mathrm{~km}$ \\
\hline$U_{\mathrm{SD}}, V_{\mathrm{SD}}$ & 10,10 & 10,10 & 10,10 & $20+2(z-80) \sin ^{2}\left(\pi t / T_{M}\right)$ & 10,10 \\
\hline$\lambda_{\mathrm{SD}}$ & $50 \mathrm{~km}$ & $50 \mathrm{~km}$ & $50 \mathrm{~km}$ & - & $50 \mathrm{~km}$ \\
\hline$U_{2 \mathrm{D}}, V_{2 \mathrm{D}}$ & $20+5 R_{0}$ & 0 & 0 & 0 & 0 \\
\hline$U_{\mathrm{GW} 1}$ & 10 & 10 & 10 & $20 a b s\left[\sin \left(2 \pi t / T_{\mathrm{M}}\right)\right] \sin \left(2 \pi t / T_{\mathrm{SD}}\right)$ & $40 F_{4}(t)$ \\
\hline$V_{\mathrm{GW} 1}$ & 0 & 0 & 0 & 0 & 0 \\
\hline$W_{\mathrm{GW} 1}$ & 5 & 5 & 5 & $-10 a b s\left[\sin \left(2 \pi t / T_{\mathrm{M}}\right) \sin \left(2 \pi t / T_{\mathrm{SD}}\right)\right]$ & $20 F_{4}(t)$ \\
\hline $\begin{array}{c}k_{1}, l_{1}, m_{1} \\
T_{\mathrm{GW} 1}\end{array}$ & $\begin{array}{cc}2 \pi / 50, & 0, \quad 0 \\
20 & \end{array}$ & $\begin{array}{ll}2 \pi / 50, & 0, \quad 0 \\
20 & \end{array}$ & $2 \pi / 50, \quad 0, \quad 0$ & $2 \pi / 50, \quad 0, \quad 0$ & $\begin{array}{lrr}2 \pi / 50, & 0, & 2 \pi / 15 \\
20 & \end{array}$ \\
\hline$U_{\mathrm{GW} 2}$ & 0 & 0 & 0 & 0 & 0 \\
\hline$V_{\mathrm{GW} 2}$ & 20 & 20 & 20 & $20 a b s\left[\sin \left(2 \pi t / T_{\mathrm{M}}\right)\right] \cos \left(2 \pi t / T_{\mathrm{SD}}\right)$ & $30 G_{4}(t)$ \\
\hline$W_{\mathrm{GW} 2}$ & 2 & 2 & 2 & $5 a b s\left[\sin \left(2 \pi t / T_{\mathrm{M}}\right) \cos \left(2 \pi t / T_{\mathrm{SD}}\right)\right]$ & $10 \mathrm{G}_{4}(\mathrm{t})$ \\
\hline$k_{2}, l_{2}, m_{2}$ & $0,2 \pi / 100,0$ & $0,2 \pi / 100,0$ & $0,2 \pi / 100,0$ & $0,2 \pi / 100,0$ & $0,2 \pi / 100,2 \pi / 20$ \\
\hline$T_{\mathrm{GW} 2}$ & 30 & 30 & 30 & 30 & 30 \\
\hline$U_{\mathrm{GW} 3}, W_{\mathrm{GW} 3}$ & - & - & $20,-10$ & $20,-10$ & - \\
\hline$k_{3}, m_{3}$ & - & - & $2 \pi / 30, \quad 0$ & $2 \pi / 30, \quad 0$ & - \\
\hline$T_{\mathrm{GW} 3}$ & - & - & $\infty$ & $\infty$ & - \\
\hline$V_{\mathrm{GW} 4}, W_{\mathrm{GW} 3}$ & - & - & 10,2 & 10,2 & - \\
\hline $1_{4}, m_{4}$ & - & - & $2 \pi / 40, \quad 0$ & $2 \pi / 40, \quad 0$ & - \\
\hline$T_{\mathrm{GW} 4}$ & - & - & $\infty$ & $\infty$ & - \\
\hline$<u^{\prime} w^{\prime}>$ mean & 25 & 25 & -75 & -100 & 50 \\
\hline$<v^{\prime} w^{\prime}>$ mean & 20 & 20 & 30 & 10 & 25 \\
\hline
\end{tabular}

* Daily mean GW momentum fluxes for each case are shown at the bottom. Units for velocities, wave numbers, and periods are $\mathrm{m} \mathrm{s}^{-1}, \mathrm{~km}^{-1}$, and min and $T_{\mathrm{M}}=10$ days, $T_{\mathrm{D}}=24 \mathrm{~h}$ and $T_{\mathrm{SD}}=12 \mathrm{~h} . R_{0}$ is a random variable between 0 and 1 chosen separately for each day. GWs in Case 4 are modulated by amplitude functions $F_{4}(t)=1\left(t=0-3 \mathrm{~h}+21 R_{1} \mathrm{~h}\right)$ and $F_{4}(t)=0$ otherwise, and $G_{4}(t)=1\left(t=0-4 \mathrm{~h}+20 R_{2} \mathrm{~h}\right)$ and $G_{4}(t)=0$ otherwise, with $R_{1}$ and $R_{2}$ random variables between 0 and 1 chosen separately for each of the 30 days of the test month.

which the accumulated values of $v_{\text {rad }}^{\prime}$ throughout the month did not reach the minimum of 30 echoes needed for Hocking's analysis. Clearly, with respect to the method's ability to deal with low meteor rates, the composite and modified composite days are better than the direct analysis. If we now look at the time averages, shown in Figs. 2b, $3 b$ and 4 b, we see that the modified composite and the direct averages give us quite similar results. However, the simple composite day analysis gives variances which are about $100 \%$ larger than either the direct analysis or the modified composite day analysis, as can be seen in the ratio between composite day (CD) and modified composite day (MCD) shown in Fig. 5. We believe that this is a result of contamination mainly by planetary waves since there is a strong quasi-2-day oscillation present in our simulation and the simple composite day is influenced by this oscillation. The $24 \mathrm{~h}$ averages for the direct 
Table 2. Ideal meteor distribution used in our simulation.

\begin{tabular}{cccccccccc}
\hline & Total & W & E & SW & NE & S & N & SE & NW \\
\hline Meteor counts & 21802 & 3994 & 2914 & 3796 & 3077 & 2083 & 1931 & 1817 & 2190 \\
\hline
\end{tabular}

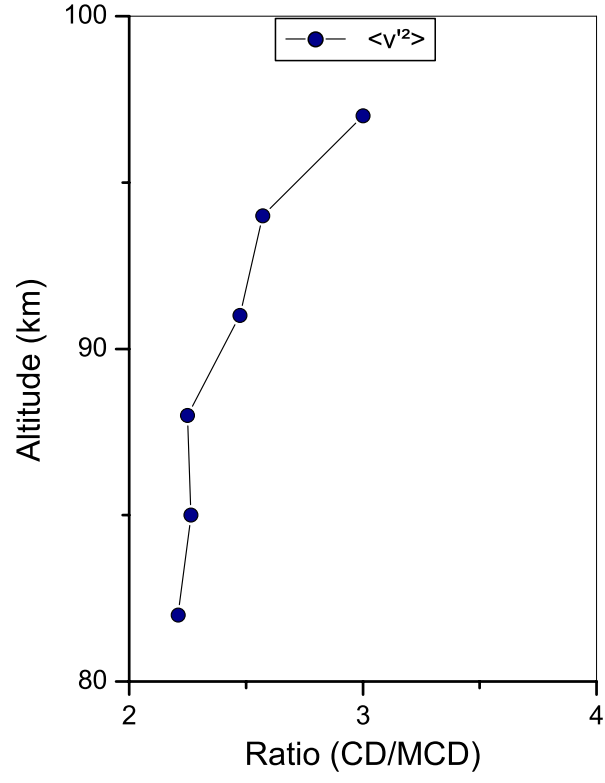

Fig. 5. Ratio of the composite to the modified composite day meridional variances.

analysis and the modified composite day analysis are fairly similar, although, as expected, there is more scatter in the direct analysis results. Even though MCD and direct analysis show similar values, both overestimate the expected values for the variances. This appears to be caused by tidal influence on the variances measured by Hocking's analysis and will be discussed in the next section.

It is clear that the modified composite day analysis gives better results than either of the alternative techniques - direct analysis and composite day. In computing monthly (or longer period) averages, it provides better time/height coverage than the direct analysis and prevents the contamination by planetary waves or day-to-day tidal variability to which the composite day analysis is prone. We believe that the modified composite day analysis is the best procedure to employ when using Hocking's technique to derive GW fluxes from simple all-sky meteor radar data. Note that the new agile meteor radars, SAAMER and DRAAMER (Fritts et al., 2010, 2012), are able to measure GW momentum fluxes with better time resolution, making contamination by tides and planetary waves less important. To evaluate the ability of the modified composite day analysis to infer GW momentum fluxes, we have made some tests, which will be described in Sect. 3 .

\section{Empirical method for removing the apparent GW variances from Hocking's analysis}

An obvious approach to the problem of eliminating the influence of tides is to filter out the tidal components before applying Hocking's analysis. This method has been used by Fritts et al. (2010) with some degree of success. This approach, however, assumes that it is possible to determine the instantaneous tidal parameters corresponding to each detected meteor. In practice, continuous changes in tidal characteristics make this unreliable, thus limiting the degree to which the tides can be filtered out. For this reason we propose a different technique.

Looking at the contour plots of the meridional component of the GW variances, Figs. 2a and 4a, rather surprisingly, we find strong diurnal and semidiurnal variations in the variances. We can observe the tilted phase line of this structure, indicating an upward progression of the wave, typical of tides and GW. The diurnal variation of the meteor distribution, observed in Fig. 1, is caused by Earth's rotation and cannot cause a corresponding tilt in the phase. Hocking's technique, being as it is a generalization of the two-beam method developed by Vincent and Reid (1983), depends on the quasisimultaneous measurement of vertical winds at opposing azimuths. This being the case, an asymmetrical meteor distribution might lead to erroneous results. Even though it does not seem possible, however, that such an effect could cause the tide-related phase propagation visible in Figs. 2 and 4, we decided to create a constant meteor distribution with a large meteor count for a composite day in order to avoid any other possible contribution of meteor distribution in the Hocking technique. To this end we used another meteor distribution from January 2005, shown in Fig. 6, with a higher meteor rate than October 2005, and we took the geometric parameters of the meteors observed during the high detection rate time period, i.e., 07:00 to 10:00 UT, and repeated these at $2 \mathrm{~h}$ intervals throughout the day. We also redistributed the meteor detections at uniform time intervals. In this way we created an assemblage of meteor events with realistic statistics, but with a constant meteor rate. This ideal meteor distribution is shown in Table 2. It should be noted that the number of echoes is very large and constant in time for all directions.

We then applied our model winds (as in the previous case, but without the 2-day planetary wave) and computed the radial velocity for each meteor in the modified composite day. Hocking's analysis was subsequently used to estimate the variances and momentum fluxes from these fields, and a conventional winds analysis was used to estimate the mean 

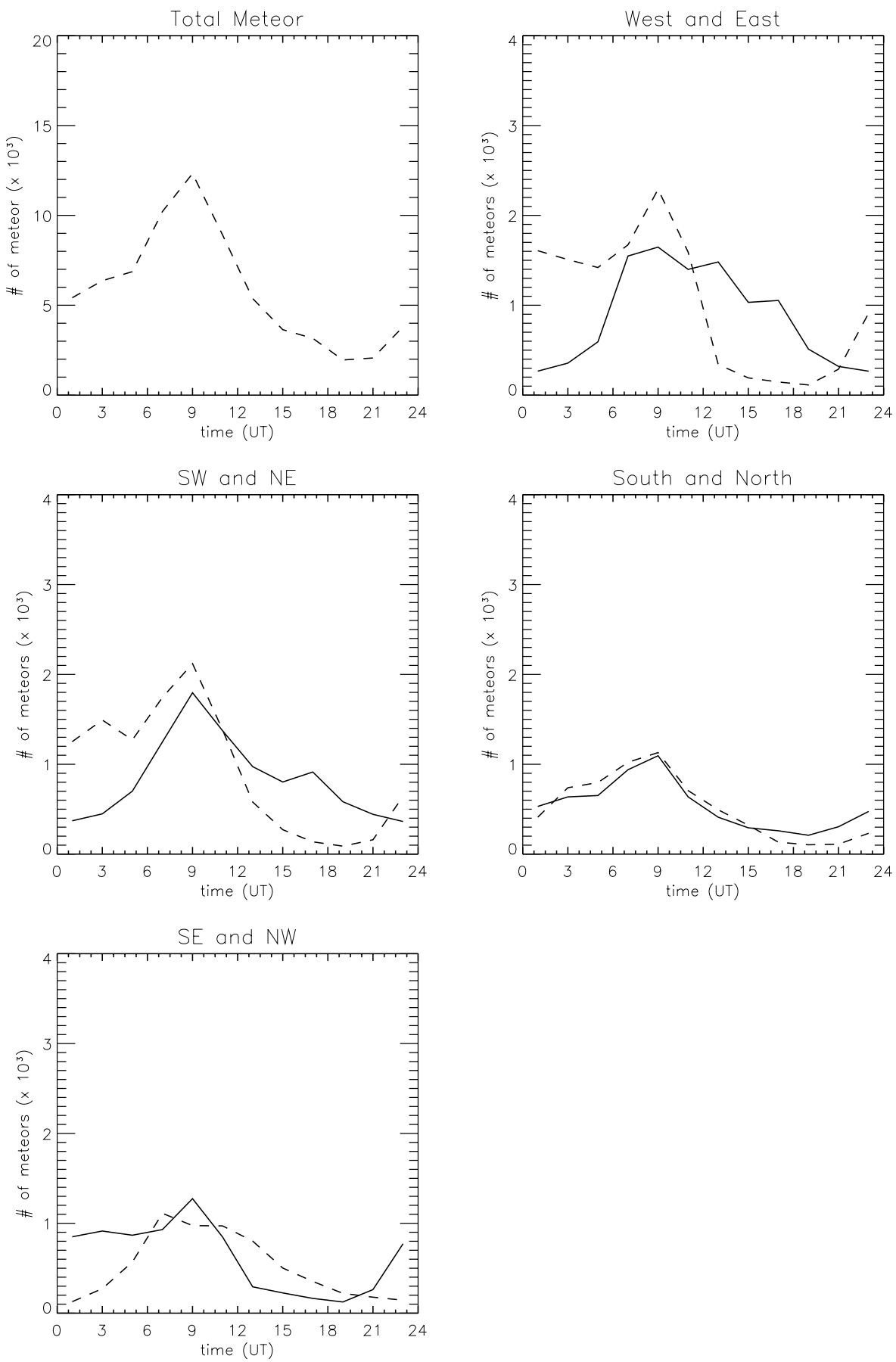

Fig. 6. As in Fig. 1 for Cachoeira Paulista during January 2005.

winds and tides. Figure 7 shows time-height contour plots of the variance components (left side) and the vertical flux of horizontal momentum (right side) for this meteor distribution using the modified composite day analysis.

It is clear that the structure visible in Fig. 7 must be an artifact of the analysis since the modeled GWs are constant in time. Note that the strong structure in the variance plots cannot be a result of the diurnal variation in meteor rate since we eliminated this variation before carrying out the analysis. It is interesting to compare the contour plots of variance shown in Fig. 7 with the total wind shown in Fig. 8. Comparing these figures we can note that the maximum variance occurs where the wind is zero and the wind shear is therefore maximum. It should be pointed out here that Beldon and Mitchell (2010), using the measured fluctuations in the radial velocity of meteors as a measure of GW activity, found a semidiurnal 

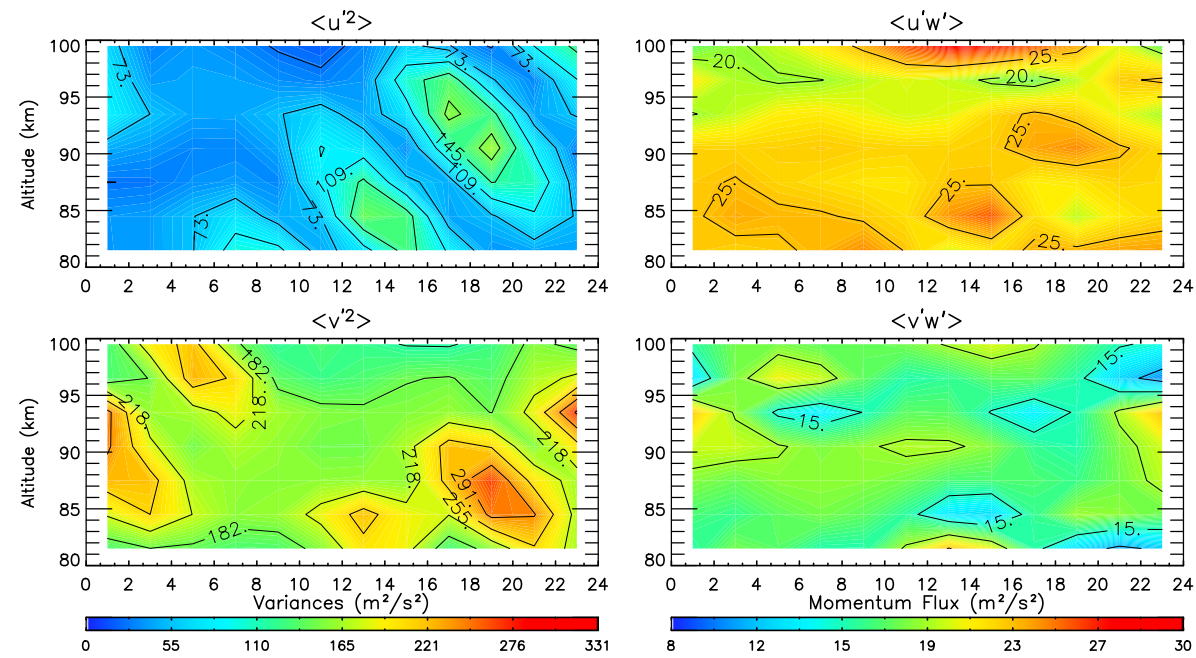

Fig. 7. Variance (left) and momentum flux (right) from Hocking's analysis. These are for $2 \mathrm{~h}$ time bins and $3 \mathrm{~km}$ high intervals.
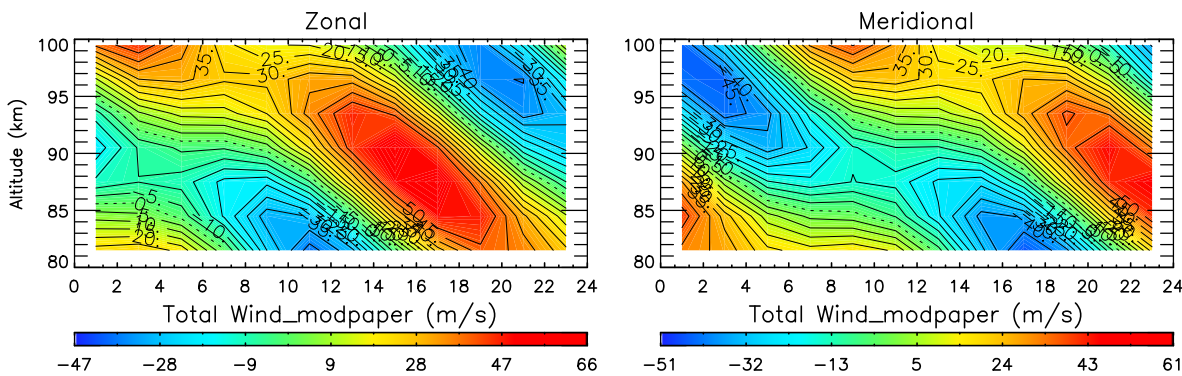

Fig. 8. Total wind velocity used in the model, zonal (left), and meridional (right). Dotted lines indicate zero wind.

modulation in the mesospheric wind variances over Rothera $\left(68^{\circ} \mathrm{S}, 68^{\circ} \mathrm{W}\right)$, which they attributed to $\mathrm{GW} /$ tidal interaction. In view of the results presented here, it seems possible that the apparent interaction between tides and GW discussed by Beldon and Mitchell might well be an artifice of the technique used. To make a more thorough study of the origin of this modulation in the variances, we used the same simulation but without any GWs, and we still found large and strongly modulated variances. This can be seen in Fig. 9, where we show the result of setting the GW amplitude to zero. On the right side of this figure we can see that both components of the momentum flux are almost zero, as expected. However, looking at the variances on the left side of Fig. 9, even though we do not simulate any GWs in this test, we still have nonzero values for variances in the output of Hocking's analysis. This means that these variances are not due to GW and need to be compensated if we want to use the variances as indicators of GW activity.

With different height and time intervals (not shown here) we have observed that the variances increase with increasing height and time intervals, and that they are also inversely proportional to the vertical tidal wavelength. This is because Hocking's method assumes that the uniform horizontal wind does not change within the time and height intervals used in the analysis. This can be seen when we reduce the time interval to $1 \mathrm{~h}$ and the height interval to $1 \mathrm{~km}$, as shown in Fig. 10. The values for the variances are reduced to one third of the previous values. Unfortunately, this does not solve our problem because reducing the time/height interval reduces the meteor count, leaving insufficient meteors for the technique to work, especially at the edges of the meteor ablation region. Moreover, it is important to remember that our tests have been made with an ideal meteor distribution. In the real world, using SKiYMET data, we need to use an interval of at least $2 \mathrm{~h}$ in time and $3 \mathrm{~km}$ in height in order to get enough meteor echoes to be able to make a wind analysis. It is clear from the results shown in Fig. 11 that, even with an ideal meteor distribution, tidal winds will lead to apparent GW variances that do not correspond to real GWs.

Placke et al. (2011a, b) removed the apparent variances due to the vertical wind shear by using the following equation,

$\overline{u_{\text {Shear }}^{\prime 2}}=\frac{1}{N-1} \sum_{i=1}^{N}\left(\left(z_{i}-z_{0}\right) \frac{\partial \bar{u}}{\partial z}\right)^{2}$, 

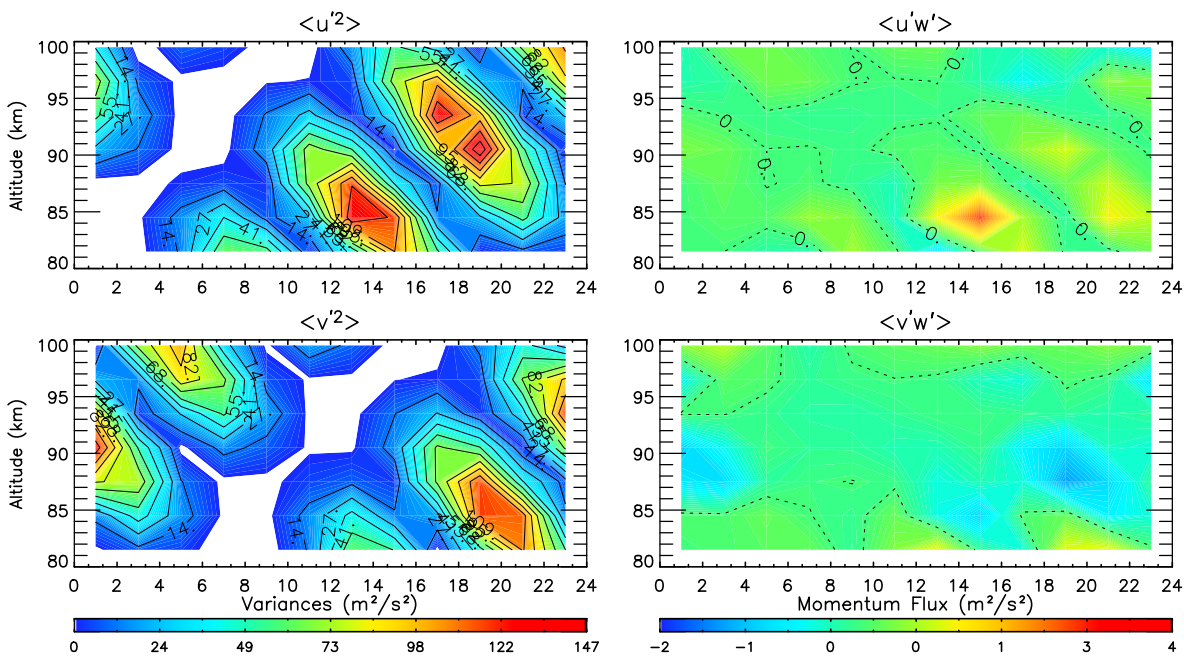

Fig. 9. Variances and momentum fluxes from Hocking's analysis using simulation without GWs.
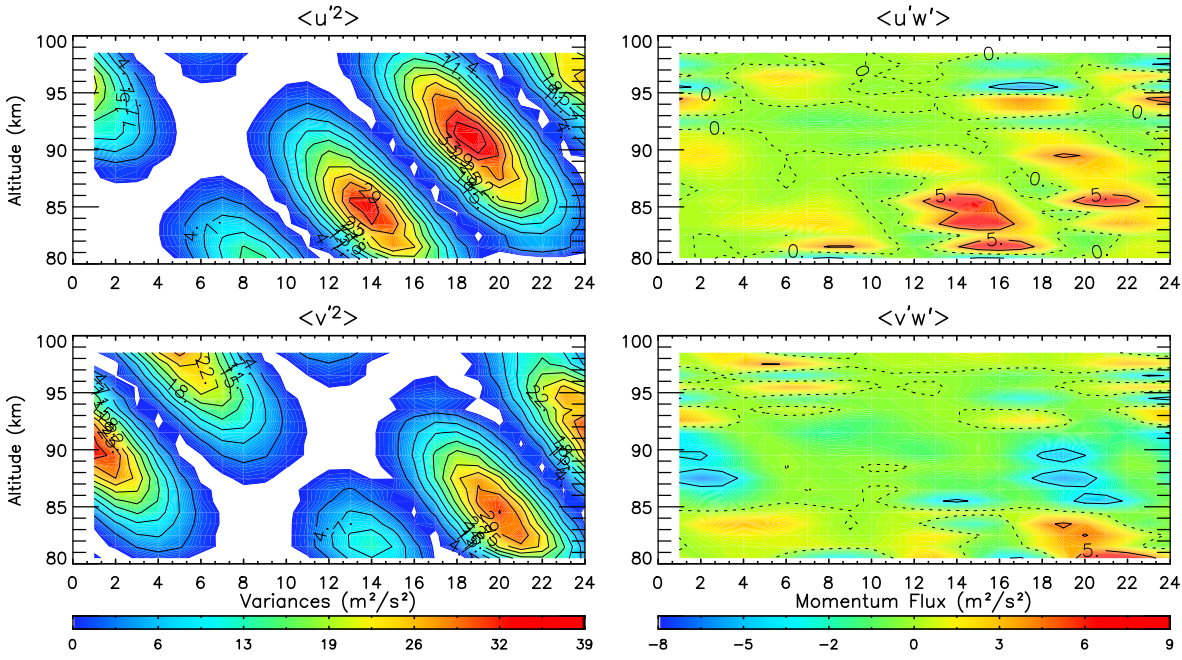

Fig. 10. As Fig. 9, but using intervals of $1 \mathrm{~h}$ in time and $1 \mathrm{~km}$ in height. The values for the momentum fluxes have been multiplied by 10 .

where $N$ is the number of meteor echoes, $z_{i}$ is the height of the respective meteor and $z_{0}$ is the reference altitude or the center of the height bin, and the last term is the measured vertical wind shear. This would be efficient enough if the shear was only in the vertical; however, in a $2 \mathrm{~h}$ time interval it is easy to verify that the tidal wind could vary several $\mathrm{m} \mathrm{s}^{-1}$ and hence contribute to the variances in Hocking's analysis. In the following paragraphs we suggest a technique that solves this problem.

The way we propose to remove the tide-induced variances, leaving variances that really correspond only to $\mathrm{GW}$, is divided into three steps. In the first step we infer tidal fields and total variances using Hocking's method. In the second step we use the tidal parameters from the first step as input for a model to simulate the wind field and estimate the apparent variances due to this wind. Finally, we subtract the appar- ent variances from the total, leaving only the variances due to GW. Note that this analysis is made using the data from a complete month in a modified composite day analysis.

Our method involves the following steps:

1. compute the total horizontal wind in each time/height interval;

2. infer $v_{\text {rad }}^{\prime}$ for each meteor detected in each of these intervals;

3. fit the total winds at each altitude with sliding 4-day fits to the tidal and 2-day wave amplitudes and phases;

4. create a composite day on the basis of the $v_{\text {rad }}^{\prime}$ values and the angular information;

5. infer the resulting GW variances and momentum fluxes; 

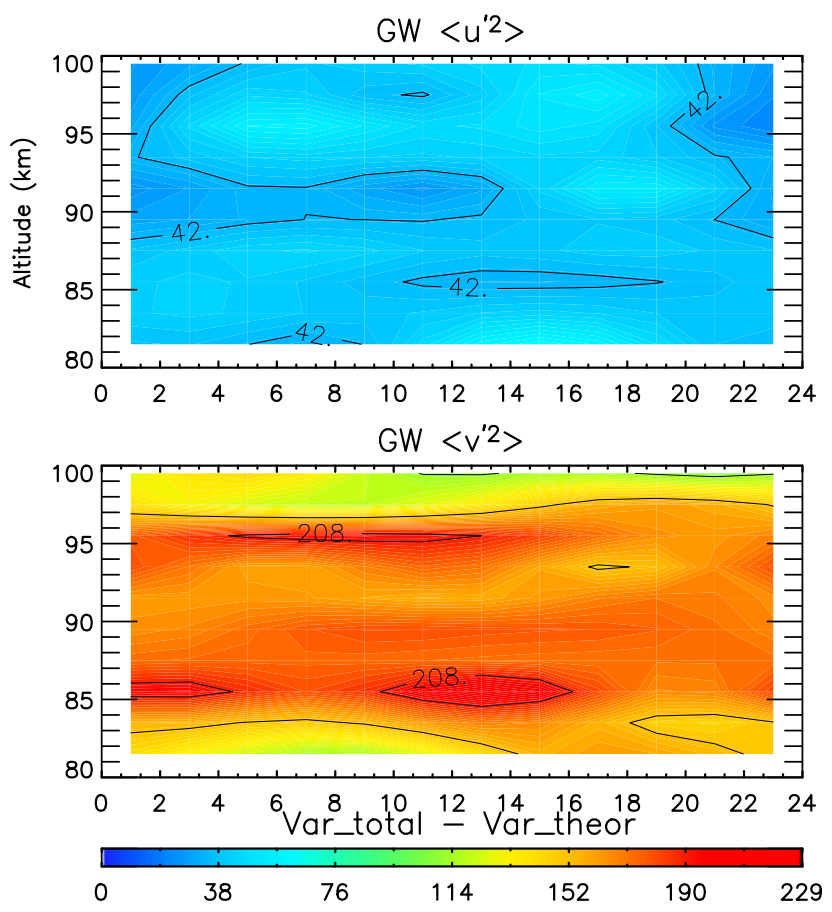

Fig. 11. GW variances after removing tidal contamination. The upper and lower panels show the zonal and meridional components, respectively.

6. build a second composite day with the fitted tidal and planetary wave (PW), by replacing the measured $v_{\mathrm{rad}}^{\prime}$ of each meteor by the modeled one using the fitted tidal and PW parameters determined in step 3;

7. compute the artificial apparent variances for this second "tidal and PW" composite day;

8. subtract the artificial variances from those inferred in step 5.

To test our method, we have used the Case 0 parameters shown in Table 1, where we have two constant GWs. For this case, the analytical variances expected from the model are $50 \mathrm{~m}^{2} \mathrm{~s}^{-2}$ and $200 \mathrm{~m}^{2} \mathrm{~s}^{-2}$ for the zonal and meridional components, respectively. In Fig. 11 we show the result of removing the apparent tidal variances (shown in Fig. 9) from the total that was shown in Fig. 7. It can be seen that the "tidal" modulations have disappeared and the values for both GW components are reasonably well recovered.

\section{Evaluation of Brazilian meteor radars GW momen- tum flux measurement capabilities}

The three Brazilian meteor radars are all SKiYMETs and are well distributed in latitude, ranging from low (São João do Cariri; $7^{\circ} \mathrm{S}, 36^{\circ} \mathrm{W}$ ) to subtropical latitudes (Cachoeira Paulista $\left(23^{\circ} \mathrm{S}, 45^{\circ} \mathrm{W}\right)$, and Santa Maria, $\left.\left(30^{\circ} \mathrm{S}, 54^{\circ} \mathrm{W}\right)\right)$.
Various studies have shown the ability of these radars to measure slowly varying winds like tides and planetary waves (Andrioli et al., 2009; Batista et al., 2004; Lima et al., 2004, 2005, 2006, 2007; Buriti et al., 2008) and also to study wind variances (Clemesha and Batista, 2008; Clemesha et al., 2009). Although these latter studies concern wind variances related to GWs and both have used Hocking's method, no detailed evaluation was made to verify the applicability of Hocking's (2005) method to the measurement of GW variances and momentum fluxes.

Based on tests that Fritts et al. (2010) made to evaluate SAAMER's abilities to measure GW momentum fluxes, we follow their procedure with the aim of doing the same for the Brazilian radars. The diurnal variation of total meteor detections separated into the eight primary angular sectors (between 15 and $50^{\circ}$ off zenith) for a composite day (i.e., total over 31 days for each $2 \mathrm{~h}$ of universal time) during January 2005 are shown in Fig. 6. In this figure dashed lines represent meteor counts for the west, southwest, south, and southeast directions, while the full lines represent the counts in the east, northeast, north, and northwest directions. Total flux is shown in the first panel. From this figure it is possible to note a large diurnal variation in the total meteor counts and the angular asymmetry in meteor detection. This diurnal variation associated with the angular asymmetry produces some regions with lower meteor counts that make it almost impossible to infer momentum flux daily. However, we will demonstrate below that using the modified composite day analysis, SKiYMET radars achieve sufficient meteor counts to yield valid monthly means of GW momentum flux estimates for various test models including mean, tidal, and GW fields. This is because by using a modified composite day, based on a whole month's data, we have a large number of meteor echoes, improving the statistics when using Hocking's analysis. Our analysis uses a least-mean-square fit to the wind, before creating composite days as explained previously, and also to recover the winds and tidal fields, as well as Hocking's (2005) technique for GW momentum flux estimates for the residual fields (after the main wind components have been removed).

\subsection{Case 1}

Figure 12 shows the monthly mean of specified and recovered fields for Case 1, using actual meteor distributions in space and time for January 2005 to estimate these fields. The parameters used in this case are shown on Table 1. The tides were assumed to have temporal and vertical variations, $25 \mathrm{~km}$ for the diurnal tide vertical wavelength and $50 \mathrm{~km}$ for the semidiurnal. The GWs have horizontal variations, with 50 and $100 \mathrm{~km}$ wavelengths in the zonal and meridional motions, respectively. These calculations show good agreement, with the mean and tidal winds very well recovered, and GW momentum flux estimates that are approximately accurate to $\sim 5 \%$ at the altitudes where the meteor counts are higher, 

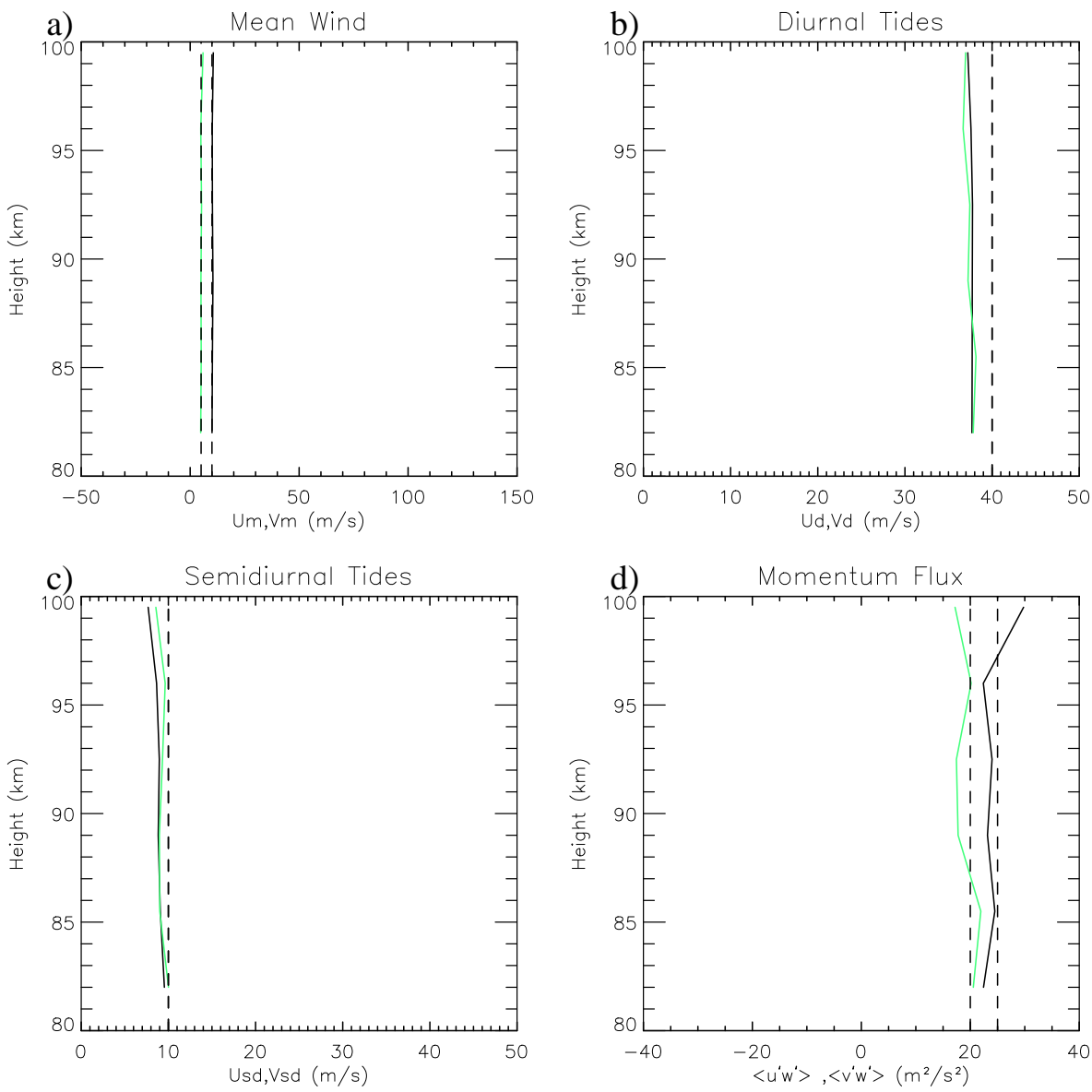

Fig. 12. Monthly specified (dashed) and recovered (solid) distributions of (a) zonal (black) and meridional (green) mean winds, (b) diurnal tide amplitudes, (c) semidiurnal tide amplitudes, and (d) GW momentum fluxes for mean, tidal, and GW fields specified in Case 1. Recovered amplitudes and momentum fluxes were obtained with actual January 2005 meteor distributions.

around $90 \mathrm{~km}$, and $\sim 10 \%$ or worst where meteor counts are decreasing. These results are encouraging, suggesting a good ability of the modified composite technique to describe both the large scale wind fields (including tides) and GW momentum fluxes for conditions in which these fields are uniform throughout the month and where meteor detection rates are sufficiently large.

\subsection{Case 2}

Case 2 corresponds to Case 4 from Fritts et al. (2010), but having vertical phase propagation in tides. This case presents a more complex superposition of mean, tidal, and GW fields given by the sum of the various motions defined in Case 1 plus two stationary GWs having horizontal wavelengths of 30 and $40 \mathrm{~km}$, respectively, for zonal and meridional directions, and having no phase variation. This case differs from the previous case in that both zonal and meridional momentum fluxes now have contributions from stationary and propagating GWs having different spatial structures (Fritts et al., 2010). In Fig. 13 we can see that the motions are well re- covered, showing the ability of the modified composite day analysis to measure a superposition of stationary and propagating GWs with an accuracy of $\sim 7 \%$ in the region where the meteor counts are highest.

\subsection{Case 3}

Case 3 was simulated exactly as Case 5 described by Fritts et al. (2010), except that we include diurnal tide phase propagation. We investigate a superposition of larger mean winds, diurnal tide, and a semidiurnal tide that exhibits both a 10-day amplitude modulation and amplitude growth with altitude, and superposed GWs having zonal and meridional propagation. As described by Fritts et al. (2010) GWs in zonal and meridional direction include a propagating $\mathrm{GW}$ modulated in amplitude and direction of propagation (and momentum flux magnitude and sign) by the semidiurnal tide and a stationary GW with constant amplitude and momentum flux. Also considered, in the present case, are semidiurnal tide components and GWs having no vertical phase variations. In order to evaluate the radar's ability to infer the momentum flux 

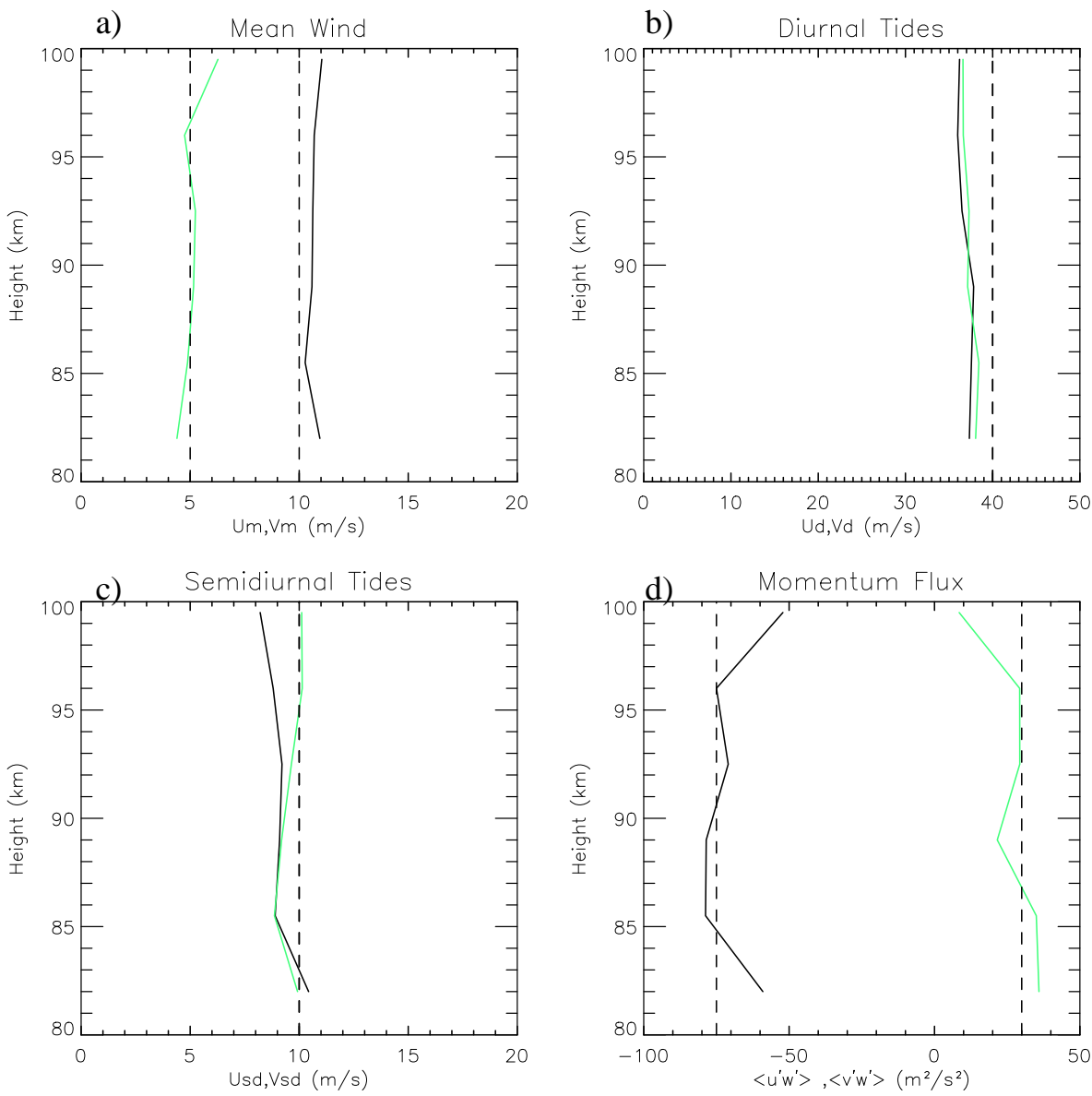

Fig. 13. As in Fig. 12, but for (a) mean winds, (b) and (c) diurnal and semidiurnal tides, and (d) the superposition of the zonal and meridional propagating GWs and stationary GWs (see Case 2 in Table 1).

due to several GWs having different spatial and temporal patterns, their four horizontal wavelengths are all different (i.e., $30,40,50$, and $100 \mathrm{~km})$.

In Fig. 14, panels (a) and (b), we show the semidiurnal tide throughout the modified composite day. Specified and recovered fields are shown with dashed and solid lines, respectively, with $20 \mathrm{~m} \mathrm{~s}^{-1}$ offsets between successive $3 \mathrm{~km}$ altitude intervals. It can be seen that the fields are very well recovered from 82 to $92.5 \mathrm{~km}$. In panels (c) and (d), we show the momentum fluxes, for a GW modulated by the semidiurnal tide, again using a modified composite day analysis and the same height intervals. A time interval of $2 \mathrm{~h}$, plus $1 \mathrm{~h}$ overlap, was used and the offsets between the successive plotted height intervals are $50 \mathrm{~m}^{2} \mathrm{~s}^{-2}$. Again we can see the very good accuracy in recovering the specified momentum fluxes for heights where the meteor counts are high. The result of superposing both zonal and meridional stationary GWs and GWs modulated by tides are shown in panels (e) and (f). The accuracy in recovering the specified fields is also good when capturing the overall magnitudes and temporal variability. The last panel shows the monthly mean for the superposed GW fields, and the accuracy for the meridional component it is $\sim 10 \%$ or better, while for the zonal component is $\sim 10-15 \%$ or worse.

Mean winds and the diurnal tide recovered for 1-day fits are shown at the top of Fig. 15. We can see that the scatter is large at the edges of the height range, around 82 and $99.5 \mathrm{~km}$. Panels (c) and (d) show, respectively, the zonal and meridional semidiurnal tide in 1-day fits throughout the month showing the modulation due to a 10-day planetary wave. Dashed and solid lines represent the specified and recovered fields with successive profiles offset by $20 \mathrm{~m} \mathrm{~s}^{-1}$. Again the accuracy is better at points where the meteor count is large.

\subsection{Case 4}

Case 4 examines the ability of the method to recover GW momentum fluxes for two transient GW packets that occur randomly for 3 or $4 \mathrm{~h}$ each day, with periods of 20 or $30 \mathrm{~min}$, zonal and meridional propagation, and both horizontal and vertical phase variations. The GWs are superposed on nominal mean winds and diurnal and semidiurnal tides having realistic amplitudes. As in Case 1, diurnal and semidiurnal 

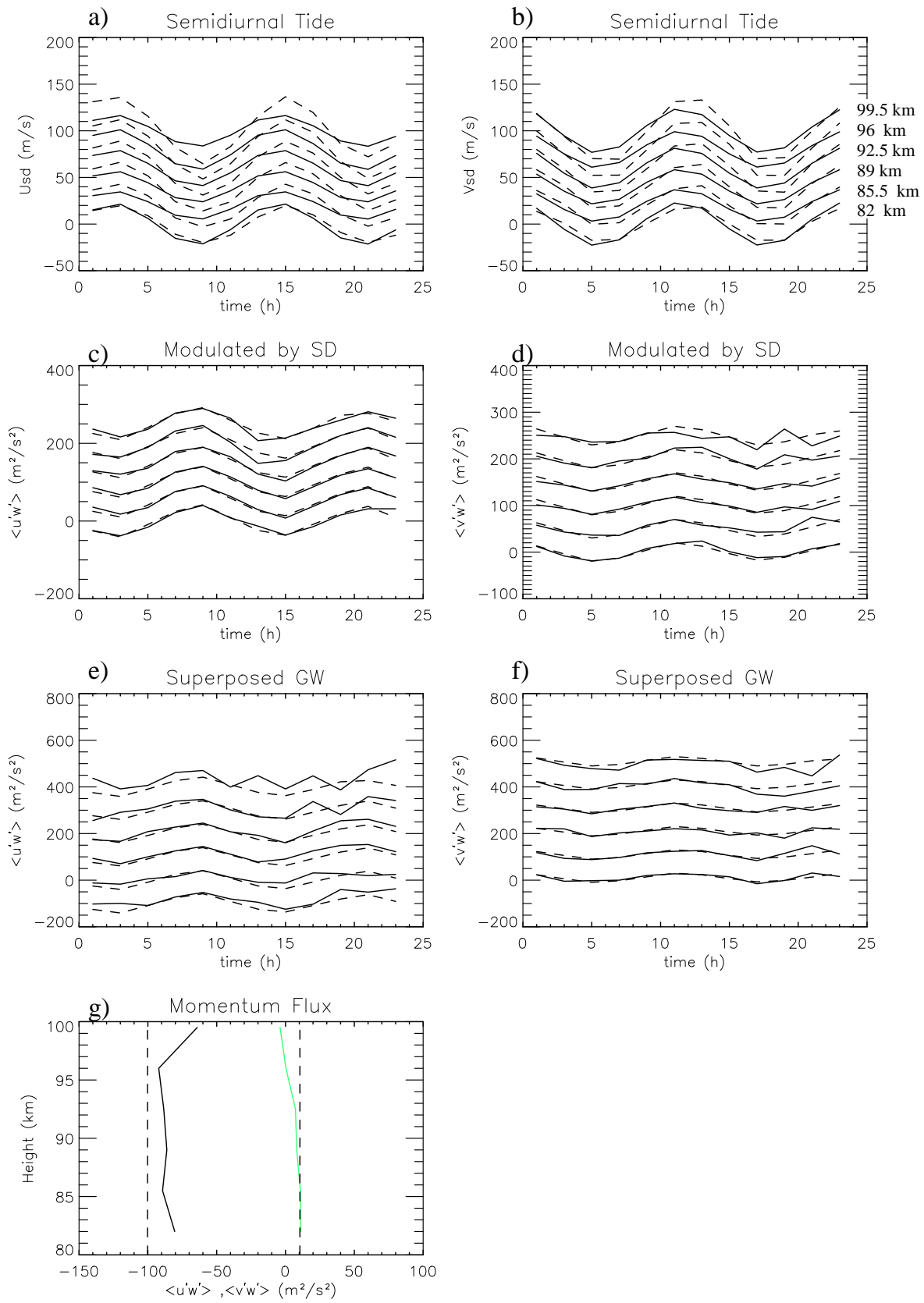

Fig. 14. (a) and (b) composite day hourly semidiurnal tides for Case 3. (c) and (d) zonal and meridional composite day hourly GW momentum fluxes for the GWs modulated by the semidiurnal tide. (e) and (f) zonal and meridional composite day hourly GW momentum fluxes for the superposition of zonal and meridional stationary GWs and the GWs modulated by the semidiurnal tide. Specified and recovered fields are shown with dashed and solid lines, respectively; offsets plotted between successive $3 \mathrm{~km}$ altitudes are $20 \mathrm{~m} \mathrm{~s}^{-1}$ for the semidiurnal tide and $50 \mathrm{~m}^{2} \mathrm{~s}^{-2}$ for the GW momentum fluxes. Altitudes range from 82 to 99.5 in each panel. Small meteor detection rates limited measurement accuracies at the highest and lowest altitudes.

tides have vertical wavelengths of 25 and $50 \mathrm{~km}$, respectively (see Table 1 for details). The constant mean winds and tidal amplitudes are recovered well for Case 4, as for Cases 1, 2 and 3 above, and are not shown in the figure.

GW occurrences and monthly mean momentum fluxes for a random distribution are shown in the lower right panel of
Fig. 16. GW vertical velocities for the 31 days (with $w^{\prime}=20$ or $10 \mathrm{~m} \mathrm{~s}^{-1}$ for the GWs propagating zonally and meridionally, respectively) are displayed at the top left, with successive daily plot offsets of $40 \mathrm{~m} \mathrm{~s}^{-1}$. Composite day variations of mean zonal and meridional momentum fluxes in the topright and bottom-left frames show maxima centered on the 

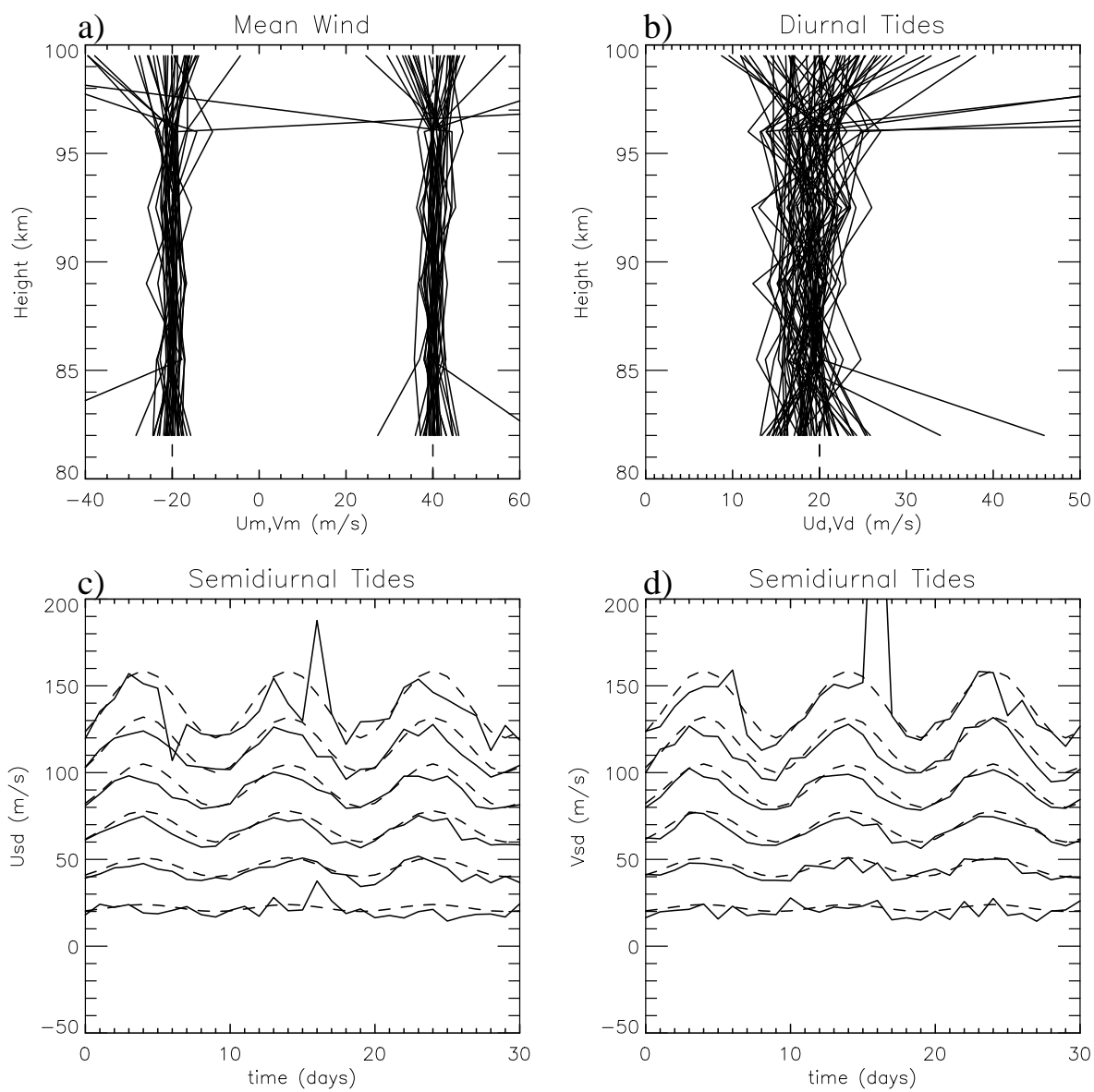

Fig. 15. (a) Daily zonal $\left(\sim 40 \mathrm{~m} \mathrm{~s}^{-1}\right)$ and meridional $\left(\sim-20 \mathrm{~m} \mathrm{~s}^{-1}\right)$ mean winds, (b) diurnal tide amplitudes, and (c) and (d) semidiurnal tide amplitudes for 1-day fits (solid) to the specified motion field in Case 3 (dashed lines) assuming the meteor distribution observed for January 2005. Successive profiles in panels (c) and (d) are offset by $20 \mathrm{~m} \mathrm{~s}^{-1}$.

intervals 1 to 9 and 14 to $17 \mathrm{~h}$ for the zonal component and 2 to 5 and 9 to $18 \mathrm{~h}$ for the meridional - in good agreement with the model input where estimates are possible. Mean momentum flux profiles shown for these zonal and meridional GW distributions reveal quite accurate estimates of the meridional momentum fluxes at lower and intermediate altitude, but underestimate the zonal momentum fluxes by $\sim 10-20 \%$, with larger underestimates at highest altitudes.

Our results are very encouraging when comparing with Fritts et al. (2010) taking into account the fact that SAAMER has a much larger meteor count. In most of the cases our results show similar accuracies for the momentum fluxes, $\sim 5 \%$ or better for Case 1, and 10-20\% for Cases 3 and 4 . Only for Case 2 does SAAMER show clearly much better accuracy. Although the results are not shown here, we also have reproduced Cases 2, 3, and 7 of Fritts et al. (2010). Cases 2 and 3 have tested the radar's ability to infer momentum fluxes of stationary GW, and we have found the same accuracy as Fritts et al. (2010). Their Case 7 investigates the radar's ability to infer momentum flux from GWs that occur randomly in packets having 2 or $1 \mathrm{~h}$ duration, similar to Case 4 shown here. Unlike Case 4, however, Case 7 reveals an apparent inability of our radar to accurately estimate momentum fluxes for highly transient GW packets. In contrast, SAAMER can estimate zonal and meridional momentum fluxes with uncertainties of only $\sim 5$ to $10 \%$ and $\sim 20$ to $25 \%$ (apart from individual outliers at the lowest and highest altitudes), respectively. Thus, the use of the modified composite day analysis as an improvement in the direct use of Hocking's analysis is seen to be the great value, at least when using the modified composite day analysis with monthly means in the region of high meteor rate, from $88 \mathrm{~km}$ to $92 \mathrm{~km}$.

\subsection{Measurement errors}

We have also made a Monte Carlo simulation in order to evaluate the contribution of measurement errors to the error in the derived variances and momentum fluxes. To this end we take a month of experimental data, and by using a modified composite day analysis we infer the variances and momentum fluxes. The meteor radar software provides the uncertainty in the radial velocity of each meteor echo, and 
a)
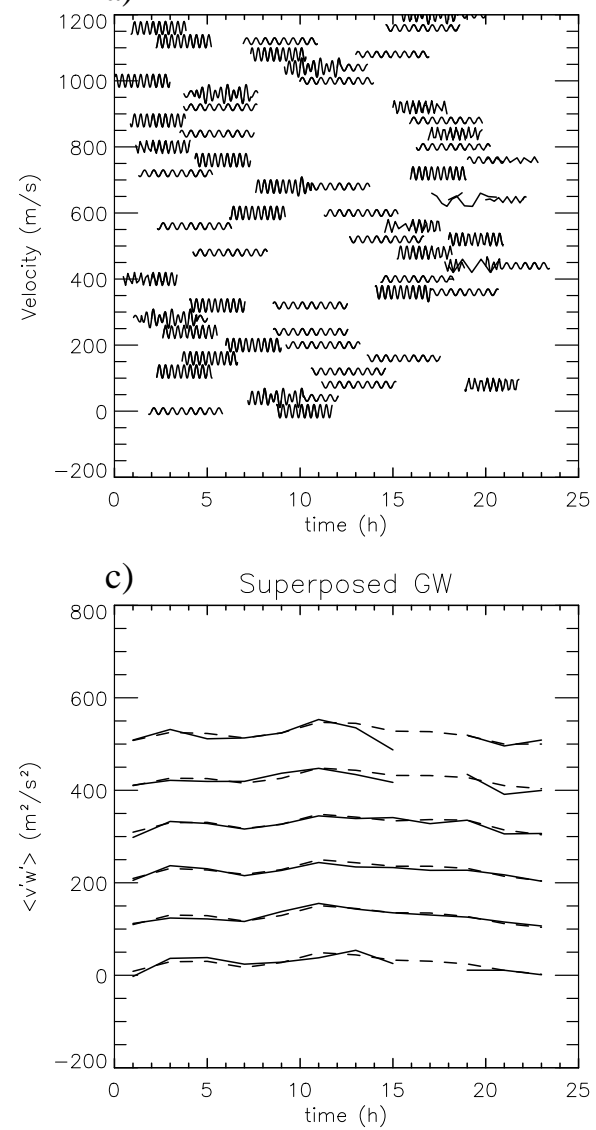

b)

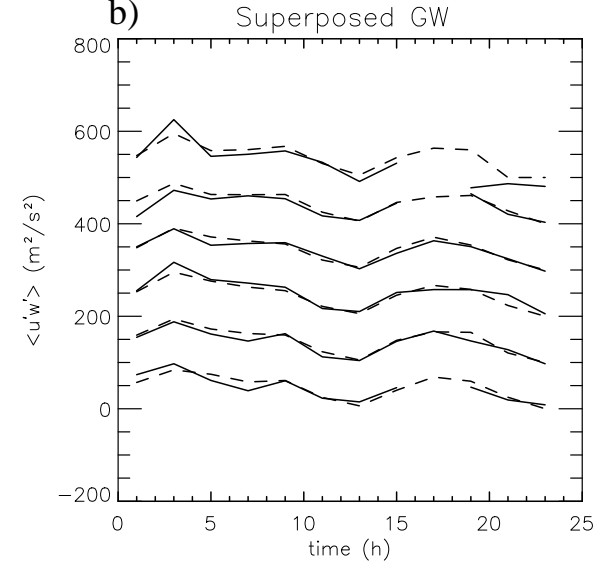

d)

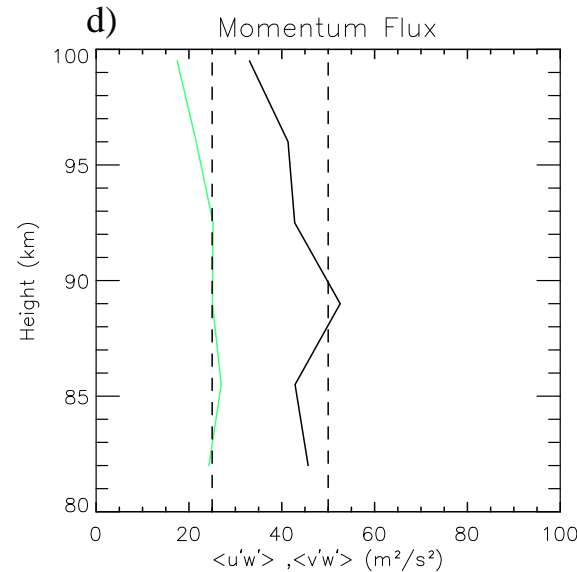

Fig. 16. (a) Vertical velocities showing the occurrence of random superposed GWs throughout the assumed test interval of CP January 2005. Vertical velocities of 20 and $10 \mathrm{~m} \mathrm{~s}^{-1}$ indicate occurrences of GWs having 3 and $4 \mathrm{~h}$ durations and propagating in the zonal and meridional directions, respectively (successive daily offsets are $40 \mathrm{~m} \mathrm{~s}^{-1}$ ). (b) and (c) diurnal variations of momentum flux throughout the composite day. (d) Monthly mean profiles of the zonal and meridional momentum fluxes inferred for January 2005 meteor distributions based on the GW occurrences shown in panel (a).
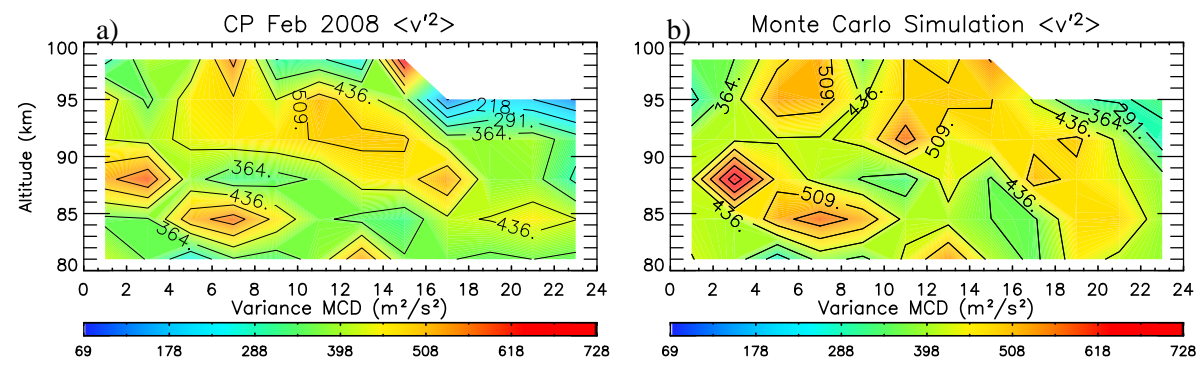

Fig. 17. (a) Meridional variance for Cachoeira Paulista on February 2008 without the measurements uncertainties contribution. (b) The same as (a) but including the error contribution in a Monte Carlo simulation with 15000 iterations.

we assume one degree for both the zenith and azimuth angle uncertainties. Then we compute the error propagation into the wind fit, assuming an appropriate random signal to include these uncertainties when inferring the $v_{\text {rad }}^{\prime}$ in Hocking's analysis. We repeat the process 15000 times and average the results. In this way we can estimate the contribution of measurement uncertainties to the variances and momentum fluxes with an error less than $2 \%$. In Fig. 17a we show the meridional component of the variance for Cachoeira Paulista in February 2008 calculated without including the measurement errors, and Fig. $17 \mathrm{~b}$ - the same quantity but including the Monte Carlo simulation of the error. As it can be seen, the error contribution is low and can be neglected. 

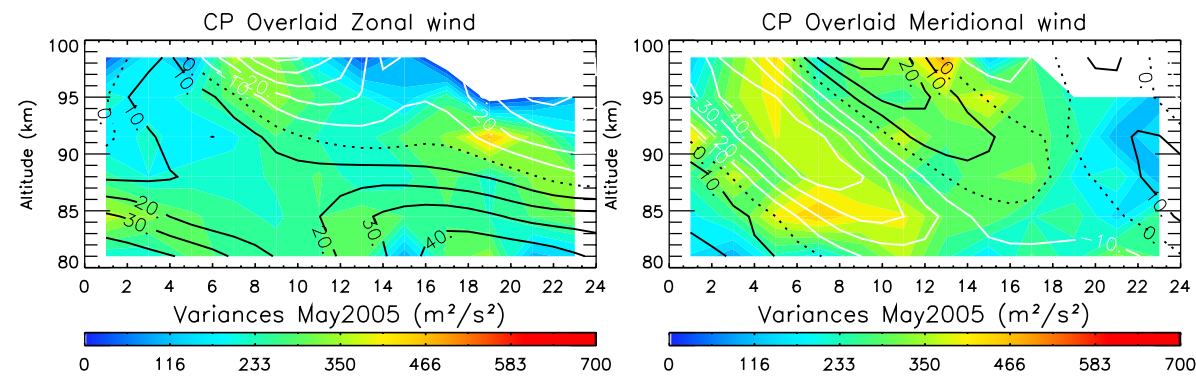

Fig. 18. Zonal (left) and meridional (right) wind variances for May 2005 over Cachoeira Paulista $\left(23^{\circ} \mathrm{S}, 45^{\circ} \mathrm{W}\right)$ using MCD analysis. The line contour overlaying the variances is the total wind, black lines mean positive values, and white lines negative values. The dashed line indicates where the wind is zero.
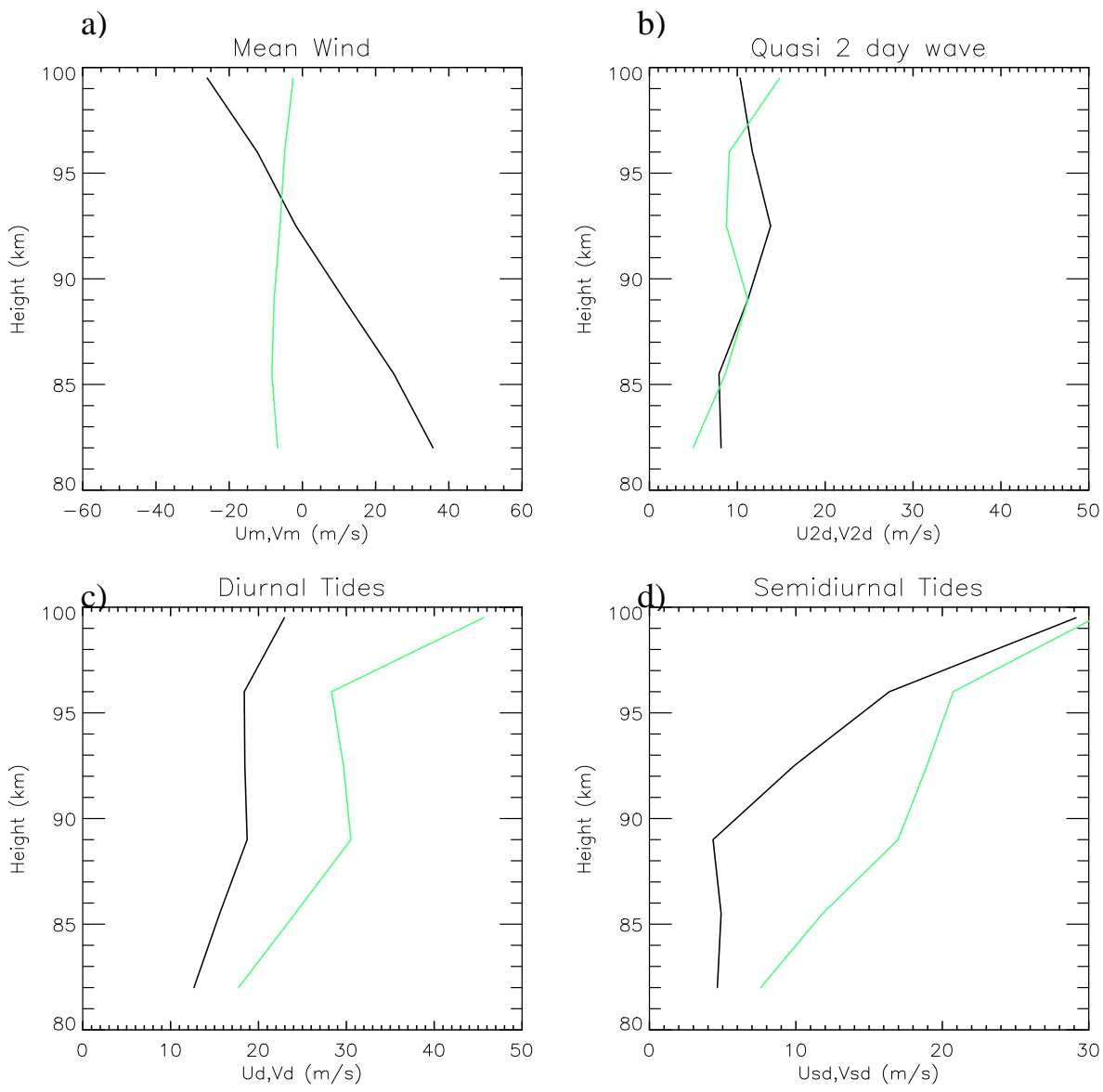

Fig. 19. Monthly measurement of (a) zonal (black) and meridional (green) mean winds, (b) quasi-two day planetary wave amplitudes, (c) diurnal tide amplitudes, and (d) semidiurnal tide amplitudes, for CP May 2005 using MCD analysis.

\subsection{Sample results}

We have also applied the MCD analysis to 2-month data from CP, May and June 2005, in order to see if our technique works well with real data. In Fig. 18 we show the wind variances for May 2005 over CP, the color contours represent the variance values for zonal (left) and meridional (right) components and the contour lines represent the total wind measured in each height/time interval. The black lines overlaying the variance values indicate positive values, while the white ones indicate negative values of the total wind, and the dashed line shows where the wind is zero. The amplitude of mean winds, quasi-2-day PW, diurnal tide, and semidiurnal tide are shown in Fig. 19 panels (a), (b), (c), and (d), respectively. We can see clearly that the amplitudes of the diurnal and semidiurnal tides have almost the same magnitude, 

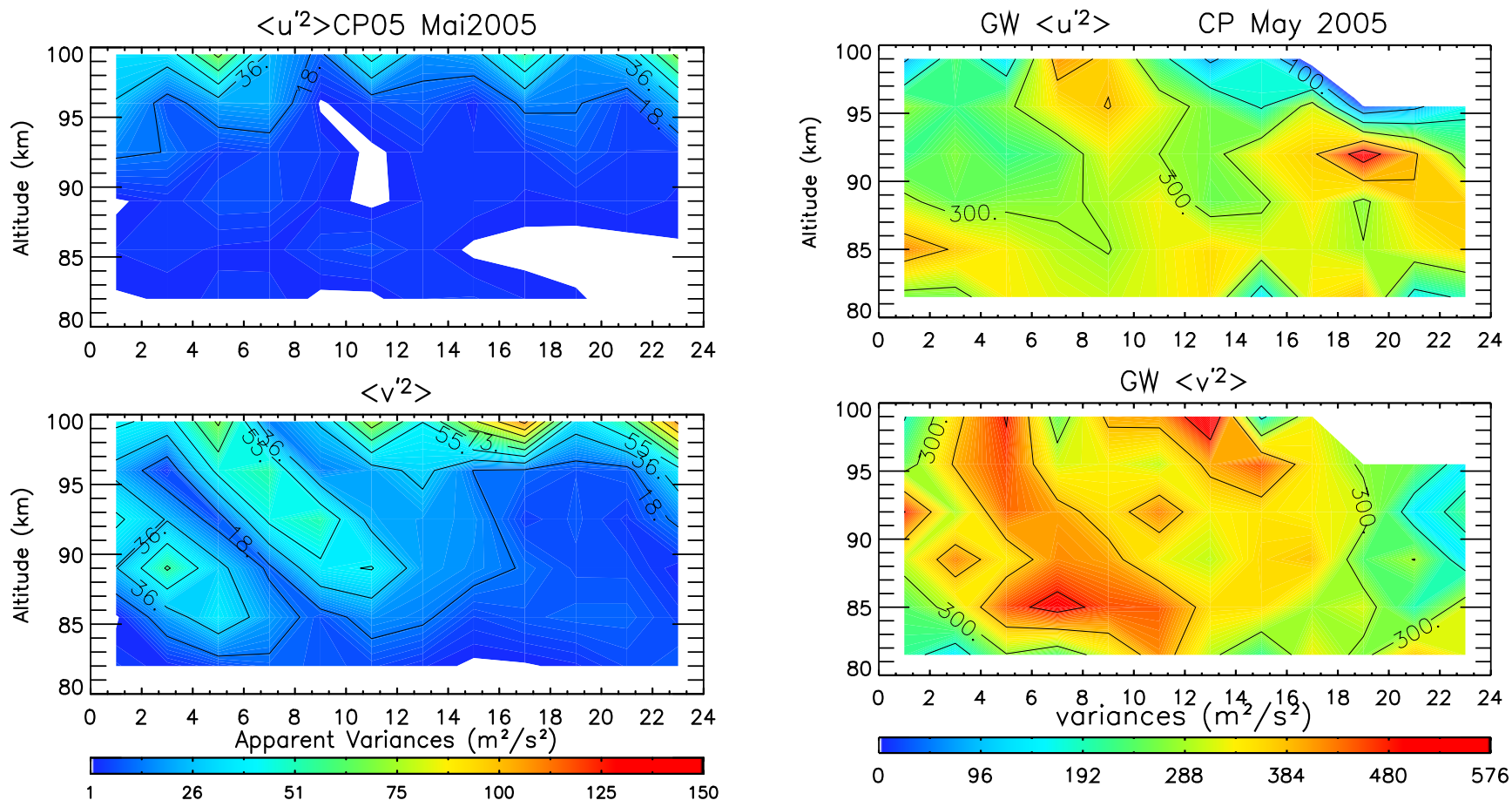

Fig. 20. Zonal (top) and meridional (bottom) apparent wind variances for May 2005 over Cachoeira Paulista $\left(23^{\circ} \mathrm{S}, 45^{\circ} \mathrm{W}\right)$ using the simulation presented in Sect. 3 .

showing that the two tides have the same importance. Also, the quasi-2-day PW has significant amplitude, $\sim 10 \mathrm{~m} \mathrm{~s}^{-1}$, remaining approximately constant with altitude. As the diurnal tide is not dominant, having the same relevance as the semidiurnal or quasi-2-day PW, and these last two have large vertical wavelengths, we do not expect much contribution to the apparent variances as seen in Fig. 20. Although the magnitudes of apparent variances are not very large, they are still significant and should be removed from the variances determined by Hocking's (2005) analysis. Note that the meridional component of the apparent variances has larger amplitudes than the zonal, which is a consequence of the meridional diurnal tide amplitude being almost twice the zonal. May and June have almost the same prevailing wind pattern and therefore they present similar structures of tidal-induced apparent variances; thus, we omit here the MCD steps for June 2005 presenting only the final variance results.

In Figs. 21 and 22 we show the wind variances for zonal $\left(<u^{\prime 2}>\right.$, top) and meridional $\left(<v^{\prime 2}>\right.$, bottom) components for CP in May 2005 and June 2005 with the apparent (false) variances already removed - in other words keeping only the wind disturbances really due to GW activity. We can see that the variance values range from 100 to $600 \mathrm{~m}^{2} \mathrm{~s}^{-2}$, which are in good agreement with the results present by Antonita et al. $(2008)$ over Trivandrum $\left(8.5^{\circ} \mathrm{N}, 76.9^{\circ} \mathrm{E}\right)$, from 100 to $500 \mathrm{~m}^{2} \mathrm{~s}^{-2}$. Moreover, we can also see that the wind variances in the meridional component are larger than the

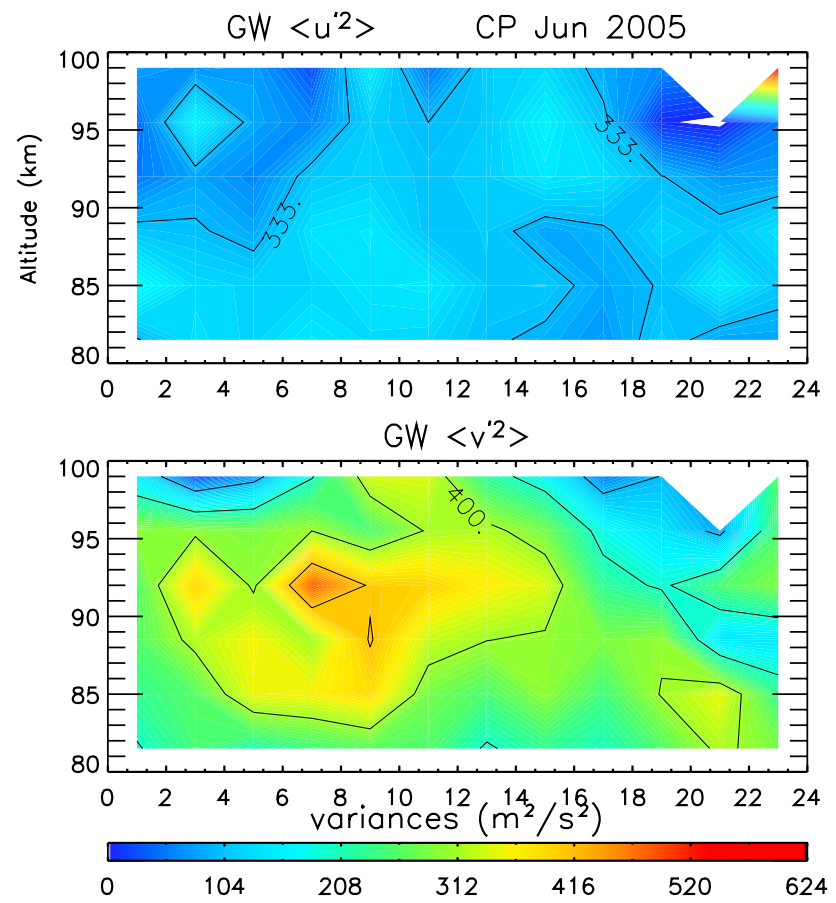

Fig. 22. The same as Fig. 21, but for June 2005. 
works with real data. A more detailed analysis of the results using the MCD technique will be presented in the near future.

\section{Summary and conclusions}

We have presented a modified composite day analysis of allsky meteor radar data as an extension of Hocking's (2005) technique for inferring GW variances and momentum fluxes in the presence of significant tidal and PW variability. Our analysis has shown that our modified composite day method yields more accurate results than either the simple composite day analysis or simple day-to-day averages. This analysis involved five test cases including various combinations of the zonal and meridional mean winds, diurnal and semidiurnal tides, a 2-day wave, and GWs having various characteristics. The diurnal tide had a vertical wavelength of $25 \mathrm{~km}$ and amplitude independent of altitude and time. The semidiurnal tide had a vertical wavelength of $50 \mathrm{~km}$ and amplitude that was either constant or varied with altitude and time. Traveling GWs were specified to have zonal, meridional, and/or oblique propagation, spatial and temporal variability, correlated horizontal and vertical motions, and both constant and variable momentum fluxes; stationary GWs were specified to have zonal and meridional orientations, only spatial variability, correlated horizontal and vertical motions, and constant momentum fluxes.

Recovered fields indicate a modified composite day ability to characterize mean and tidal wind fields very well at all altitudes. Monthly GW momentum fluxes for constant stationary or propagating GW fields were also retrieved with high accuracy (errors of a few percent) at those altitudes where the meteor counts are high (from 89 to $92.5 \mathrm{~km}$ ). GW momentum flux estimates exhibited somewhat larger errors, however, when the amplitude of the semidiurnal tide was large and modulated in time, especially at altitudes and time intervals where meteor counts were lower (around midnight UT).

Our modified composite day analysis has also shown reasonable ability to extract momentum fluxes of transient GWs having durations of $\sim 3 \mathrm{~h}$ or longer, periods of $20-30 \mathrm{~min}$, and random distributions throughout the diurnal cycle. The analysis was not so successful, however, when GW packet durations were $2 \mathrm{~h}$ or less with opposing contributions to the net GW momentum flux in some directions. The same tests were also performed for the two other Brazilian SKiYMET meteor radars (not shown), and they yielded similar results, showing the reasonable ability of SKiYMET meteor radars to measure monthly mean GW momentum fluxes in cases when GWs are not highly variable in time.

We have also shown that estimates of GW variances using the Hocking (2005) analysis can be contaminated by tidal fluctuations. This is due to the fact that we cannot achieve sufficiently small time/height bins with sufficient meteor counts within which the largely tidal wind does not change. To address this problem, we developed a technique for deter- mining the magnitude of the apparent variances contributed by tides and PWs, which can then be subtracted from the total variances determined by the Hocking technique. Numerical simulations using realistic tide and GW parameters showed that our technique is successful in largely removing contamination by tides. We note that momentum flux measurements are not significantly influenced by tidal contributions to apparent GW variances. This is because momentum flux estimates employ correlations between horizontal and vertical velocities, to which tides contribute very little.

We consider our modified composite day analysis to be potentially useful to the broader community, given the large number of meteor radars currently in operation and the need for more global assessments of GW momentum fluxes as inputs to our various modeling needs.

Acknowledgements. The author V. F. Andrioli would like to acknowledge the CAPES foundation for the scholarship number BEX 0107/11-5. Support for D. Fritts was provided by NSF grant OPP0839084.

Topical Editor C. Jacobi thanks G. Stober and one anonymous referee for their help in evaluating this paper.

\section{References}

Andrioli, V. F., Clemesha, B. R., Batista, P. P., and Schuch, N. J.: Atmospheric tides and mean winds in the meteor region over Santa Maria $\left(29.7^{\circ} \mathrm{S} ; 53.8^{\circ} \mathrm{W}\right)$. J. Atmos. Solar-Terr. Phys., 71, 1864 1876, doi:10.1016/j.jastp.2009.07.005, 2009.

Antonita, T. M., Ramkumar, G., Kumar, K. K., and Deepa, V.: Meteor wind radar observations of gravity wave momentum fluxes and their forcing toward the Mesospheric Semiannual Oscillation, J. Geophys. Res., 113, D10115, doi:10.1029/2007JD009089, 2008.

Batista, P. P., Clemesha, B. R., Tokumoto, A. S., and Lima, L. M.: Structure of the mean winds and tides in the meteor region over Cachoeira Paulista, Brazil $\left(22.7^{\circ} \mathrm{S} ; 45^{\circ} \mathrm{W}\right)$ and its comparison with models, J. Atmos. Solar-Terr. Phys., 66, 623-636, doi:10.1016/j.jastp.2004.01.007, 2004.

Beldon, C. L. and Mitchell, N. J.: Gravity wave-tidal interactions in the mesosphere and lower thermosphere over Rothera, Antarctica $\left(68^{\circ} \mathrm{S}, 68^{\circ} \mathrm{W}\right)$, J. Geophys. Res., 115, D18101, doi:10.1029/2009JD013617, 2010.

Buriti, R. A., Hocking, W. K., Batista, P. P., Medeiros, A. F., and Clemesha, B. R.: Observations of equatorial mesospheric winds over Cariri $\left(7.4^{\circ} \mathrm{S}\right)$ by a meteor radar and comparison with existing models, Ann. Geophys., 26, 485-497, doi:10.5194/angeo26-485-2008, 2008.

Clemesha, B. R. and Batista, P. P.: Gravity waves and windshear in the MLT at $23^{\circ} \mathrm{S}$, Adv. Space Res., 41, 1471-1476, doi:10.1016/j.jastp.2008.01.013, 2008.

Clemesha, B. R., Batista, P. P., Buriti da Costa, R. A., and Schuch, N.: Seasonal variations in gravity wave activity at three locations in Brazil, Ann. Geophys., 27, 1059-1065, doi:10.5194/angeo27-1059-2009, 2009.

Fritts, D. C., Janches, D., and Hocking, W. K.: Southern Argentina Agile Meteor Radar: Initial assessment of gravity 
wave momentum fluxes, J. Geophys. Res., 115, D19123, doi:10.1029/2010JD013891, 2010.

Fritts, D. C., Janches, D., Hocking, W. K., Bageston, J. V., and Leme, N. M. P.: Drake Antarctic Agile Meteor Radar (DrAAMER) First Results: Configuration and Comparison of Mean and Tidal Wind and Gravity Wave Momentum Flux Measurements with SAAMER, J. Geophs. Res., 117, D1027, doi:10.1029/2011JD016651, 2012.

Hocking, W. K.: A new approach to momentum flux determinations using SKiYMET meteor radars, Ann. Geophys., 23, 2433-2439, doi:10.5194/angeo-23-2433-2005, 2005.

Hocking, W. K., Fuller, B., and Vandepeer, B.: Real-time determination of meteor-related parameters utilizing modern digital technology, J. Atmos. Solar-Terr. Phys., 63, 155-169, 2001.

Lima, L. M., Batista, P. P., Clemesha, B. R., and Takahashi, H.: Quasi-two-day wave observed by meteor radar at $22.7^{\circ} \mathrm{S}$, J. Atmos. Solar-Terr. Phys., 66, 529-537, doi:10.1016/j.jastp.2004.01.007, 2004.

Lima, L. M., Batista, P. P., Clemesha, B. R., and Takahashi, H.: The 6.5-day Oscillations observed in Meteor Winds over Cachoeira Paulista $\left(22.7^{\circ}\right.$ S), Adv. Space Res., 36, 2212-2217, 2005.

Lima, L. M., Batista, P. P., Clemesha, B. R., and Takahashi, H.: 16-day wave observed in the meteor winds at low latitudes in the southern hemisphere, Adv. Space Res., 38, 2615-2620, doi:10.1016/j.asr.2006.03.033, 2006.
Lima, L. M., Paulino, A. R. S., Medeiros, A. F., Buriti, R. A., Batista, P. P., Clemesha, B. R., and Takahashi, H.: First observation of the diurnal and semidiurnal oscillation in the mesospheric winds over São João do Cariri-PB, Brazil, Rev. Bras. Geofísica 25, 35-41, doi:10.1590/S0102-261X2007000600005, 2007.

Placke, M., Hoffmann, P., Becker, E., Jacobi, C., Singer, W., and Rapp, M.: Gravity wave momentum fluxes in the MLT - Part II: Meteor radar investigations at high and midlatitudes in comparison with modelling studies, J. Atmos. Solar-Terr. Phys., 73, 911-920, doi:10.1016/j.jastp.2010.05.007, 2011a.

Placke, M., Stober, G., and Jacobi, Ch.: Gravity wave momentum fluxes in the MLT - Part I: Seasonal variation at Collm $\left(51.3^{\circ} \mathrm{N}, 13.0^{\circ} \mathrm{E}\right)$, J. Atmos. Solar-Terr. Phys., 73, 904-910, doi:10.1016/j.jastp.2010.07.012, 2011 b.

Vincent, R. A. and Reid, I. M.: HF Doppler measurements of mesospheric gravity wave momentum fluxes, J. Atmos. Sciences, 40, 1321-1333, 1983.

Vincent, R. A., Kovalam, S., Reid, M., and Younger, J. P.: Gravity wave flux retrievals using meteor radars. Geophys. Res. Lett., 37, L14802, doi:10.1029/2010GL044086, 2010. 